\title{
A PARAMETER SENSITIVITY STUDY IN THE DYNAMIC SIMULATION OF A SODIUM COOLED BREEDER REACTOR POWER PLANT
}

$$
\text { by }
$$

Gregory Joseph Kolb

\author{
A Theșis Submitted to the Faculty of the \\ DEPARTMENT OF NUCLEAR ENGINEERING \\ In Partial Fulfillment of the Requirements \\ For the Degree of \\ MASTER OF SCIENCE \\ In the Graduate college \\ THE UNIVERSITY OF ARIZONA
}


STATEMENT BY AUTHOR

This thesis has been submitted in partial fulfillment of requiremerits for an advanced degree at The University of Arizona and is deposited in the University Library to be made available to. borrowers under rules of the Library.

Brief quotations from this thesis are allowable without special permission, provided that accurate acknowledgment of source is made. Requests for permission for extended quotation from or reproduction of this manuscript in whole or in part may be granted by the head of the major department or the Dean of the Graduate College when in his judgment the proposed use of the material is in the interests of scholarship. In all other instances, however, permission must be obtained from the author.

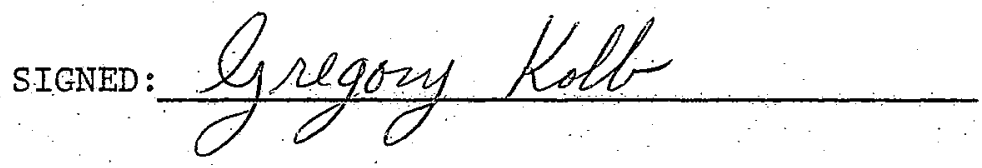

APPROVAL BY THESIS DIRECTOR

This thesis has been approved on the date shown below:

Band L Hetrich

D. I. HERRICK

Professor of Nuclear Engineering
14 December 1977

Date 
To my Mom, Dad, and wife Laura 


\section{ACKNOWLEDGMENTS}

I would Iike to thank Dr. David L. Hetrick for the invaluable assistance he gave me during the course of this study. 
TABLE OF CONTENTS

Page

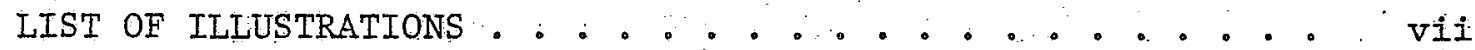

LIST OF TABLES ....................... viii

ABSTRACT . . . . . . . . . . . . ........ . . IX

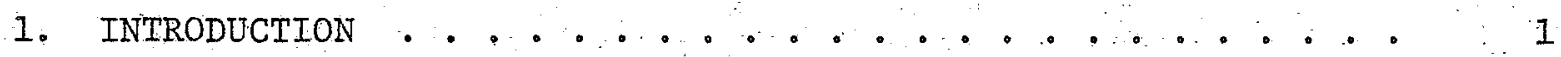

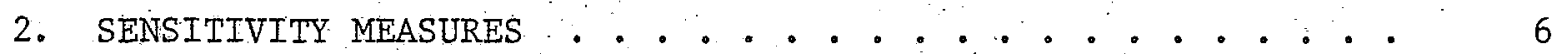

2.1 Root or Eigenvalue Sensitivity . . . . . . . . 6

2.2 Frequency Domain Sensitivity--Bode Analysis . . . . . 9

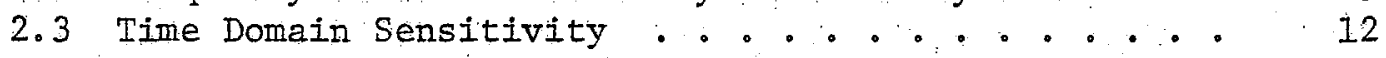

3. PARAMETER SENSITIVITY STUDY OF A CRBRP DYNAMIC SIMULATOR • • 19

3.1 Approach . ........................ 19

3.2 Parameter Sensitivity in the Primary Loop . . . . 23

$3.2 .1100 \%$ Power Level .......... 23

$3.2 .270 \%$ and $40 \%$ Power Level . . . . . . . . 32

3.3 Parameter Sensitivity in the Open Loop 34

3.4 A Method for Putting First Order Bounds on
Simulation Transients . . . . . . . . 40

4. CONCLUSIONS AND RECOMMENDATIONS $\ldots \ldots \ldots$

4.1 Conclusions . . . . . . . . . . . . . 46

4.2 Recommendations ............................ 47

APPENDIX A: PROCEDURE FOR MEETING PSAR DESIGN CONDITIONS

IN THE SUPERHEATER EXAMPLE . . . . . . . 49

A.1 H Sensitivity . ............. 50

A. $2 \mathrm{C}_{\mathrm{PWA}}^{\mathrm{WA}}$ Sensitivity

APPENDIX B: SENSITIVTTY OF DOPPLER FEEDBACK COEFFICIENT • • 53

APPENDIX C: AN EXAMPLE OF INSENSITIVITY OF CERTAIN

PARAMETERS . . . . . . . . . . . . . .

APPENDIX D: ESTIMATION OF CUT-OFF TIME AT $40 \%$ and $70 \%$

POWER LEVEL . ................ 
TABLE OF CONTENTS--Continued

Page

A.PPENDIX E: AN EXAMPLE OF PUTTING FIRST ORDER BOUNDS ON A STEP REACTIVITY TRANSIENT . . . . . . . . . 60

REFERENCES 。. • . . . . . . . . . . . . . . . . . 


\section{IIST OF ILIUSTRATIONS}

Figure

Page

I-1 Schematic Diagram of the CRBRP............... . . . 4

2-1. Bode Sensitivity of a Low Order Control System . . . . . . . II

2-2 An Illustration of the Definition of the Sensitivity Function . . . . . . . . . . . . . . . . . . . 14

2-3 Time Domain Sensitivity of the 3rd Order Superheater Model Following a $20^{\circ} \mathrm{F}$ Step in the Sodium Inlet Temperature . . 16

3-1 Schematic Diagram of the Primary Loop . . . . . . . . . 20

3-2 Schematic Diagram of the Open Loop Steam Generator . . . . 22

3-3. The Absolute Value of the Fuel Temperature Peak Sensitivity in the $40-100 \%$ Power Range ...........

3-4 The Absolute Value of the Reactor Exit Temperature Peak Sensitivity in the 40-100\% Power Range . . . . . ....

B-I Doppler Feedback Coefficient Sensitivity of the Fuel Temperature Following a 10 c step in Reactivity . . . . . .

B-2 Effects of Steam Generator Feedback on the Sensitivity of the IHX Intermediate Sodium Outlet Temperature 
Table

2-1 Root Sensitivity of the 3rd Order Superheater Model . . . .

3-I List of Parameters in the Primary Loop . . . . . . . . . . .

3-2 Peak Sensitivity Results from the Primary Loop at $100 \%$

Power Level . . . . . . . . . . . . . . . . . . .

3-3 The Absolute Value of the Peak Sensitivity Results Normalized to the Doppler Coefficient at $100 \%$ Power Level in the Primary Loop... . . . . . . . . . . . . .

3-4 PSAR Design Conditions at 40\% and 7.0\% Power Level . . . .

3-5. Peak Sensitivity Results from the Primary Loop at $40 \%$ and $70 \%$ Power Level . . . . . . . . . . . . .

3-6 The Absolute Value of the Peak Sensitivity Results Normalized to the Doppler Coefficient at $40 \%$ and $70 \%$ Power Level in the Primary Loop . . . . . . . . . . . .

3-7 List of Parameters in the Steam Generator . . . . . . ...

3-8 Peak Sensitivity Results from the Open Loop Steam Generator . . . . . . . . . . . . . . . . . .

3-9. The Absolute Value of the Peak Sensitivity Results Normalized to the Most Sensitive Parameters in the Steam Generator 


\section{ABSTRACT}

The time domain sensitivity measure, peak sensitivity, was employed in studying the dynamics of a Clinch River Breeder Reactor Power Plant (CRBRP) digital simulator. With its use the most "safety sensitive" parameters in the plant model were identified for particular anticipated transients. Examples of such parameters include the Doppler feedback coefficient, fraction of power generated in the core, and the two phase flow friction multiplier. A method of putting first order bounds on a particular power plant transient due to parameter estimate error is also presented. This information is valuable since the CRBRP simulator was constructed with the intent of studying the safety of the system. 
CHAPTER 1 .

\section{INTRODUCTION}

In a nuclear power plant model, parameters rieeded to describe the physical system may be lumped into various categories. Nuclear parameters include Doppler coefficients, delayed neutron fractions, and decay constants. Thermohydraulic parameters include heat transfer coefficients, friction factors, pump efficiencies and the like. Mechanical parameters, such as turbine time constants and inertia are also needed.

A parameter sensitivity study of a model of a dynamic system yields information as to how the characteristics of the model change when a parameter is varied. Model changes might be characterized by a difference in step response, frequency response (Bode analysis), or the location of system roots in the complex s-plane (root locus). After a sensitivity measure has been made the numerical analyst can then make judgments as to which are the most important parameters in the system model. This information is especially valuable in its application to a nuclear power plant dynamic simulator and has the following aims:

i. If a parameter is highly sensitive, then an accurate determination of it is necessary to yield good numerical results.

2. Bounding tolerances on a particular simulated power plant transient due to parameter estimate errors can be sought. (This aim is of prime importance when judging reactor safety.) 
3. In system identification work the most highly sensitive parameters are adjusted to match the model with the physical system. Other, less sensitive, parameters are usually not considered.

The goal of this thesis is the achievement of aims 1 and 2 . Since the Clinch River Breeder Reactor Power Plant (CRBRP) has not yet been constructed, the achievement of aim 3 must be postponed to a later date.

The CRBRP simulator to be considered consists of a set of coupled algebraic and ordinary differential equations (Shinaishin 1976) and are solved on a digital computer by the DARE software package (Lucas and Wait 1975). These equations describe the conservation laws of physics as applied to the various components in the CRBRP (i.e., reactor, evaporator, etc.). The space dependence has been handled by sectionalizing the system into several lumps (or nodes). The algebraic equations may be eliminated by substitution yielding the following simplified vector description of the system:

$$
\frac{d \bar{x}}{d t}=A \bar{x}+\bar{f}(\bar{x}, t)+B \bar{u}(t) ; x(0)=x_{0}
$$

where

$$
\begin{aligned}
\overline{\mathrm{x}} & \equiv \text { the state vector } \\
\mathrm{A} & \text { a matrix of constant coefficients of the linear terms } \\
\overline{\mathrm{f}}(\overline{\mathrm{x}}, \mathrm{t}) \equiv & \text { the vector of nonlinear and variable coefficient } \\
& \text { terms }
\end{aligned}
$$


$\begin{array}{ll}B & \equiv \text { a matrix of constant coefficients } \\ \bar{u}(t) & \equiv \text { forcing function vector } \\ X_{0} & \equiv \text { vector of initial conditions }\end{array}$

Parameters of interest are found within the $A$ and $B$ matrices and within the nonlinear $\overline{\mathrm{f}}$ vector.

A diagram of the CRBRP simulator with the appropriate state variable locations may be found in Figure 1-1. Also in this figure is a list of the nominal steady state initial conditions which must be met to match the plant design operating point at 100\% power level (Clinch River Breeder Reactor Project. Preliminary Safety Analysis Report [PSAR] 1975$).$ It should be understood that the CRBRP simulator considered does not contain plant controllers. These controllers (i.e., reactivity, pump speed, etc.) were not included so that the effects of intrinsic parameter variations (i.e., inherent to the natural system) on the system response would not be masked by feedback effects from the automatic controllers. In this way a better understanding of these intrinsic parameters can be achieved. Another reason is that this is also a more conservative approach when sensitivity measures are used in judging reactor safety since the loss of system controllers might possibly occur.

The sensitivity measure employed in this thesis is suited for time domain analysis. Other sensitivity measures, namely root locus and Bode analysis, were not used. The reason for this decision, along with a discussion of the sensitivity measure employed, can be found in Chapter 2. 


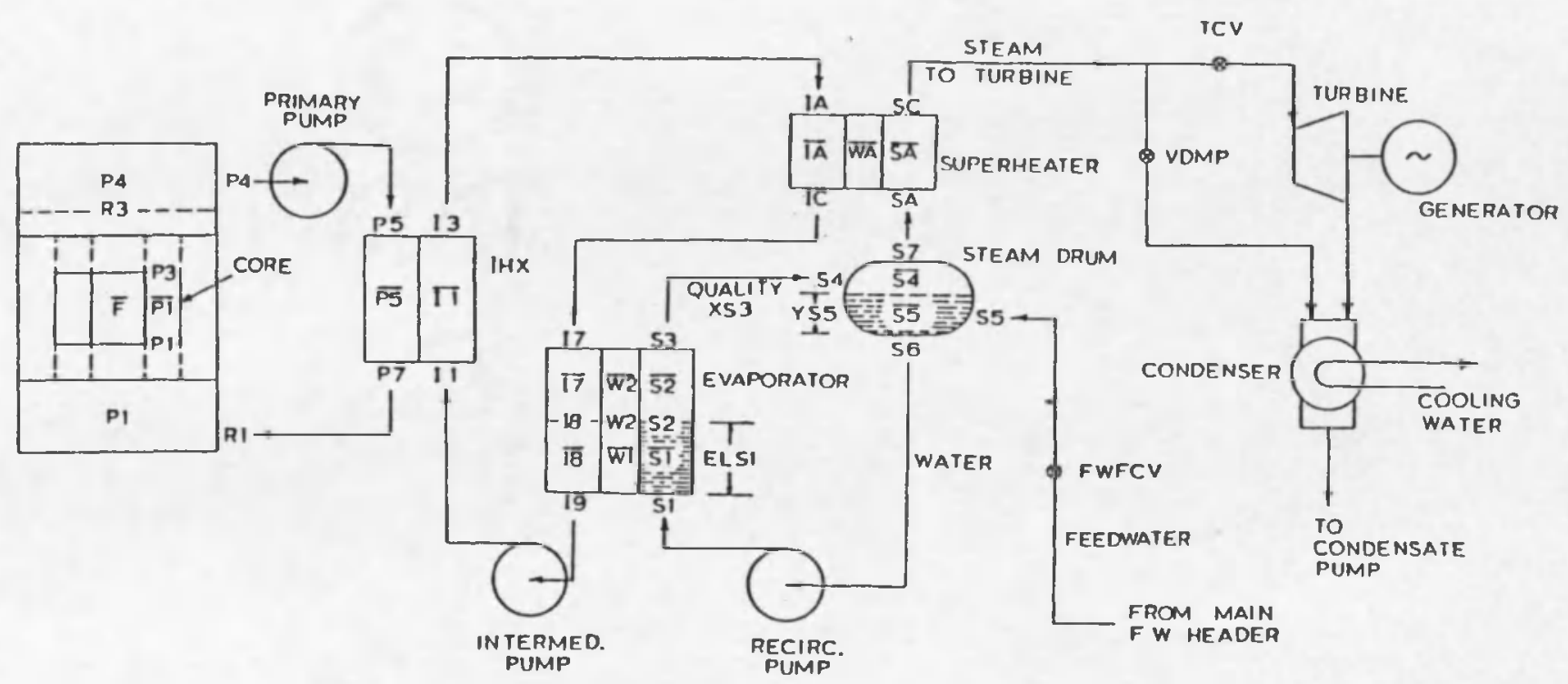

\begin{tabular}{|c|c|c|c|}
\hline Temperature & Temperature (cont.) & F1ow (cont.) & Mass \\
\hline${ }^{\bar{T}_{A F}}{ }_{T_{I C}}\left(855^{\circ} \mathrm{F}\right)$ & ${ }_{\frac{T}{T}}^{T_{R C}}{ }_{\text {SC }}\left(905^{\circ} \mathrm{F}\right)$ & $\begin{array}{l}\text { Downcomer }(18561 \mathrm{bm} / \mathrm{sec}) \\
\mathrm{S.H.-Turb1ne}(9281 \mathrm{bm} / \mathrm{sec}) \\
\text { Feedwater }(9281 \mathrm{bm} / \mathrm{sec})\end{array}$ & ${ }_{\mathrm{M}}^{\mathrm{M}}{ }_{\mathrm{M} 5}$ \\
\hline$T_{I 3}\left(936^{\circ} \mathrm{F}\right)$ & $\mathrm{T}_{\text {WA }}$ & Pressure & Water He1ght \\
\hline${ }_{I 8}^{T_{I 9}}\left(651^{\circ} \mathrm{F}\right)$ & $\overline{\mathrm{T}}_{\mathrm{W} 1}$ & $\begin{array}{l}\overline{\mathrm{P}}_{\mathrm{S} 4}(1765 \mathrm{ps} 1) \\
\overline{\mathrm{P}}_{\mathrm{S} 2}(1830 \mathrm{ps} 1)\end{array}$ & $\begin{array}{l}\mathrm{L}_{\mathrm{S} 1} \\
\text { Water Enthalp }\end{array}$ \\
\hline $\mathrm{T}_{\mathrm{P} 1}\left(730^{\circ} \mathrm{F}\right)$ & Flow & Pump Speed & $\mathrm{H}_{\mathrm{S} 6}\left(@ 544^{\circ} \mathrm{F}\right)$ \\
\hline $\begin{array}{l}{ }_{\mathrm{T} 3}^{\mathrm{P} 3} \\
\mathrm{~T}_{\mathrm{P} 7}\left(995^{\circ} \mathrm{F}\right)\end{array}$ & $\begin{array}{l}\text { Primary }(115181 \mathrm{bm} / \mathrm{sec}) \\
\text { Intermed }(106501 \mathrm{bm} / \mathrm{sec}) \\
\text { Riser }(18561 \mathrm{bm} / \mathrm{sec})\end{array}$ & $\begin{array}{l}\text { Primary (1170 RPM) } \\
\text { Intermed.(1006 RPM) }\end{array}$ & \\
\hline
\end{tabular}


Chapter 3 gives the results of the parameter sensitivity study with a discussion on its application to reactor safety. Chapter 4 is devoted to conclusions and recommendations and this will be followed by appendices containing sample calculations.

The CRBRP digital simulator to be tested for parameter sensitivity is actually one of three separate simulators developed by Shinaishin. These simulators were intended to study the safety of the CRBRP through a wide range of transients and power plant operating conditions. The second simulator is the same as the one tested in this thesis except for the plant automatic control system. These two simulators were intended to study moderate transients of the type referred to as Anticipated Transient Without Scram (ATWS). The third simulator was constructed for studying transients due to unexpected accidents followed by reactor scram. In this simulator emphasis was placed on simulating the auxiIiary heat removal system, in order to determine its capability to remove the after-shut down fission and decay heat. Together, the three simulators are known as BRENDA (Breeder Reactor Nuclear Dynamic Analysis). 
CHAPTER 2

\section{SENSITIVITY MEASURES}

Sensitivity measures generally relate the change in some system measure to the change in one or more plant parameters. A sensitivity measure should incorporate two features:

1. It should be mathematically tractable so that its utilization is not encumbered by great amounts of labor.

2. It must be physicaliy meaningful in relation to the performance of the system.

Feature number 1 is essential when testing this simulator because of its complexity and large number of parameters. Number 2 must also be met if this study is going to have anything to say about reactor safety.

\subsection{Root or Eigenvalue Sensitivity}

This sensitivity measure has been used frequently in the analysis of control systems in several fields of engineering (Van Ness, Boyle and $\operatorname{Imad}$ 1965).

The roots of a system of non-linear ordinary differential equations can be found in the following way. The equations should first be linearized about an operating point and then Laplace transforms applied. (The linearization is done by looking at sma11 perturbations about the operating point and is equivalent to removing the non-linear term in 
equation (1-1).) The roots of the system are then the solutions of the characteristic equation [1]:

$$
P(s)=\operatorname{det}[S I-A]=0
$$

Root sensitivity measures the change in position of a system root in the complex s - plane (root locus).

In the early phase of this work, root sensitivity was investigated because it had the advantage of not being dependent on the type of initiating transient, (i.e., step, ramp, frequency response of temperature, flow rate, or power). It was found, however, even for a small open loop system of equations, such as those that represent the superheater of the simulator, that the root sensitivity measure was difficult to interpret. For example, Table 2-1 contains the numerical values of the roots for the 3rd order superheater model. To calculate the parameter sensitivity a $1 \%$ error was first assumed in the estimate of the parameter of interest and then other operating conditions were adjusted, if necessary, to meet the design operating conditions specified in the PSAR (see Figure I-I and Appendix A for details). The roots of the modified system were then found by applying equation $(2-1)$. It can be seen from Table 2-I that the percentage change in root position from the nominal is greater for the first 2 roots in the sodium to wall heat transfer coefficient, while the percentage change for the $3 \mathrm{rd}$ root is greater for the superheater wall specific heat. It is therefore difficult to judge which

1. It should be noted that the linearization procedure is generally done manually, while the roots for a high order system are found by computer. There are programs which do both but the analyst loses valuable information in the process. 
Table 2-1 -- Root Sensitivity of the $3^{\text {rd }}$ Order Superheater Model.

\section{Value of Root}

Root Number

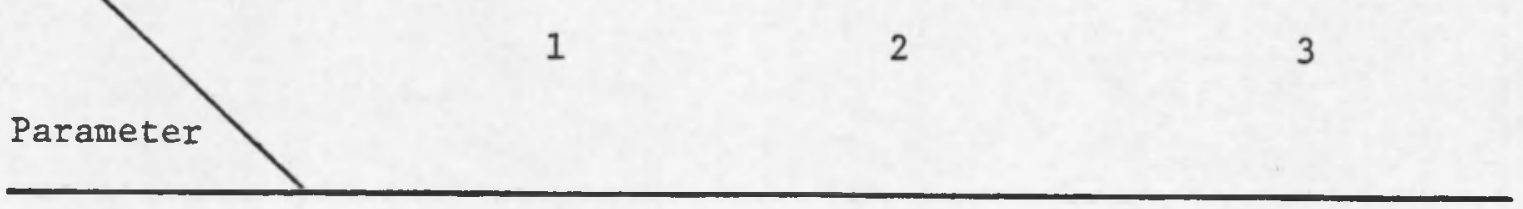

Nominal

$-6.23348$

$-2.03931$

$-0.23244$

Superheater Wa11

Specific Heat

$-6.22975$

$-2.02620$

$-0.23177$

Sodium to Wall

Heat Transfer

$-6.22573$

$-2.05783$

$-0.23246$

Coefficient

Percentage Change in Root from Nominal

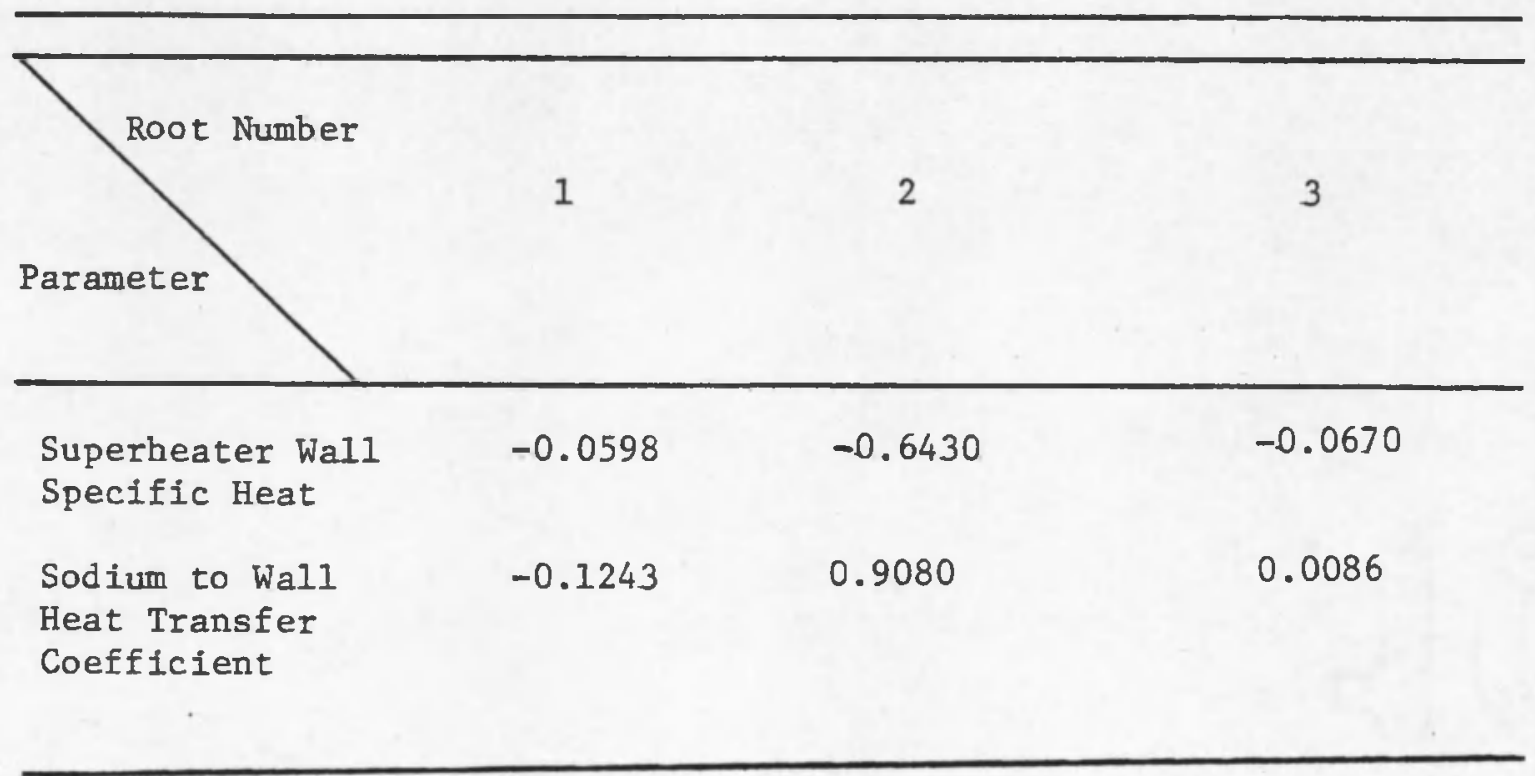


is the more sensitive parameter. Since roots are the inverse time constants of the system, a great deal of intuition must be used to correlate how the change in system roots affects the transient response. For the large system of equations present in this simulator this interpretation would become hopelessly complicated.

There are also other problems that the analyst must accept if root sensitivity is to be used. One of these problems is the great amount of labor involved in the linearization of the equations. This would be especially tedious if several operating points must be investigated for sensitivity. Probably the most serious drawback of the method, however, is that it can be shown that the system roots can change by several hundred percent with an essentially unchanged step response (Truxal 1955, p. 295). This drawback cannot be tolerated in this sensitivity study because important information as to the safety oriented time behavior of the CRBRP is lost.

2.2 Frequency Domain Sensitivity--Bode Analysis

Probably the best known sensitivity measure is classical, or Bode, sensitivity. This is defined as the percent variation of a system transfer function, $T$, with respect to the percent variation of a parameter $\lambda$, and is defined as follows:

$$
s_{\lambda}^{T}(s)=\frac{d T / T}{d \lambda / \lambda}=\frac{d(\ln T)}{d(\ln \lambda)}
$$

If the test input is a sinusoid, then $s=j \omega$, and Bode plots of equation (2-2) can be made showing the sensivitity as a function of frequency. 
Unlike root sensitivity, this sensitivity measure depends on the type of test input (1.e., flow rate and temperature transients).

Because $S_{\lambda}^{T}$ is a function of the complex variable $s$, a physical interpretation of $\mathrm{s}_{\lambda}^{\mathrm{T}}$ is difficult. As an example of where such a difficulty may occur, White (1967) conducted a sensitivity study on a class of low order linear control systems and produced the asymptotic Bode gain sensitivity curves shown in Figure 2-1. It can be noted from the figure that the parameter sensitivity is a complicated function of frequency (1.e., $k_{1}$ is the most sensitive parameter at low frequency and the least sensitive at a higher frequency). Though the results of the model tested by White have little relevance to the model tested in this thesis, it is instructive in showing a problem which may occur if this approach is taken. For this reason, and the fact that the system of equations would have to be linearized about an operating point, as in root sensitivity, this approach was abandoned.

There are, however, important applications of Bode analysis in the closely related field of system 1dentification (Chang and Kerlin 1976). The basic idea of system identification is to adjust the important (most sensitive) parameters of a model to minimize differences between experimental results obtained from the physical system and model predictions. The usual procedure is to impress a periodic test input signal $(s=j \omega)$ on a linearized set of equations, and minimize the difference between Bode plots by least squares techniques. In this discipline, working in the frequency rather than in the time domain has several important advantages. One main advantage is that by looking at 


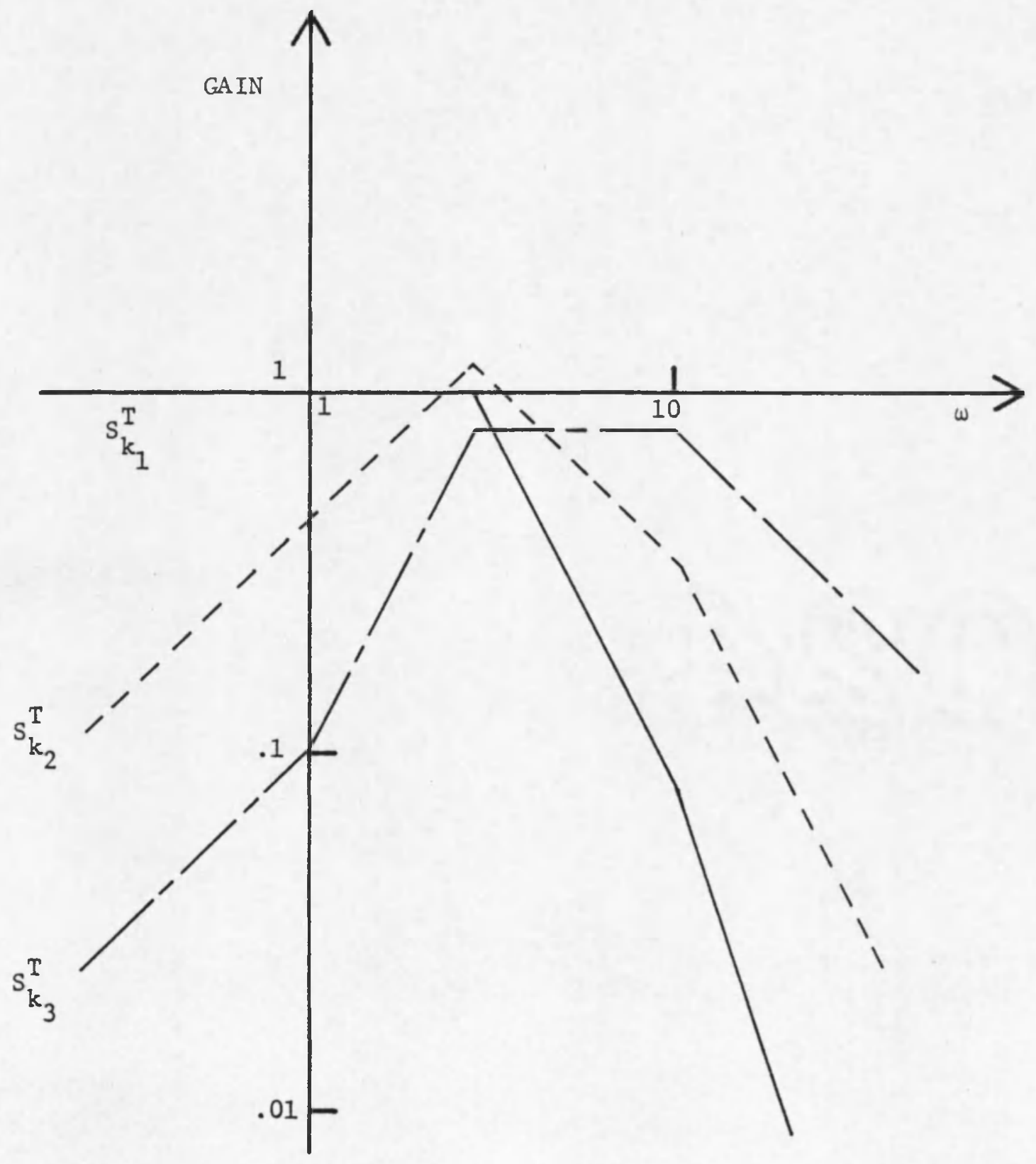

Figure 2-1 - - Bode Sensitivity of a Low Order Control System. (White 1967) 
the frequency response, low level signals can be used on the physical. system because they permit averaging of multiple estimates of the results and the background noise effect is reduced in the averaging. If a nonperiodic signal (i.e., step) is used it must be large enough in magnitude to overwhelm the background noise. However, the magnitude of such a signal is limited such that nonlinear effects do not appear and normal system operation is not disturbed.

\subsection{Time Domain Sensitivity}

The sensitivity measure used to obtain the results of this thesis was first introduced by Tomovic (1964). Let $\lambda$ be a system parameter with a nominal value $\lambda_{0}$. If $x(t, \lambda)$ is the response of a system state variable to a step input, then for a change in the parameter $\lambda$, the step response may be expanded in a Taylor series

$$
x\left(t, \lambda_{0}+\Delta \lambda\right)=x\left(t, \lambda_{0}\right)+\left.\frac{d x(t, \lambda)}{d \lambda}\right|_{\lambda_{0}} \Delta \lambda+\left.\frac{d^{2} x(t, \lambda)}{d \lambda^{2}}\right|_{\lambda_{0}} \Delta \lambda^{2}+\cdots
$$

(It should be noted that the step function is one of the standard signals used in testing systems of differential equations.) The first order effect is given by the time dependent first order sensitivity function

$$
\left.\frac{\mathrm{dx}(t, \lambda)}{\mathrm{d} \lambda}\right|_{\lambda_{0}}
$$


It is desirable to have an estimate of the change in $x(t, \lambda)$ for a percentage change in $\lambda$. Therefore, the sensitivity of the system state variables with respect to the parameter $\lambda$ is defined as:

$$
u_{\lambda_{1}}(t)=\frac{d x_{1}(t, \lambda)}{\frac{d \lambda}{\lambda}} \quad i=1, n
$$

This sensitivity measure is known as the sensitivity function (White 1967; Haberman 1977), and like Bode sensitivity, depends on the type of test input. A more concrete 1llustration of its physical meaning is shown in Figure 2-2. If a step input is applied simultaneously to both systems the differences between the outputs will be:

$$
\Delta x=x(t, \lambda+\Delta \lambda)-x(t, \lambda)
$$

Dividing by the percentage change in the parameter and letting $\Delta \lambda \rightarrow 0$, equation $(2-4)$ is obtained.

As might be expected there exists a relationship between Bode sensitivity and the sensitivity function. This was shown by White (1967) to be

$$
\mathrm{U}_{\lambda}(\mathrm{s})=\frac{1}{\mathrm{~s}} \mathrm{~T}(\mathrm{~s}) \mathrm{S}_{\lambda}^{\mathrm{T}}(\mathrm{s})
$$

where

$$
\begin{aligned}
& T(s) \equiv \text { transfer function relating input to output } \\
& \frac{1}{s} \quad \equiv \text { Laplace transform of step input }
\end{aligned}
$$




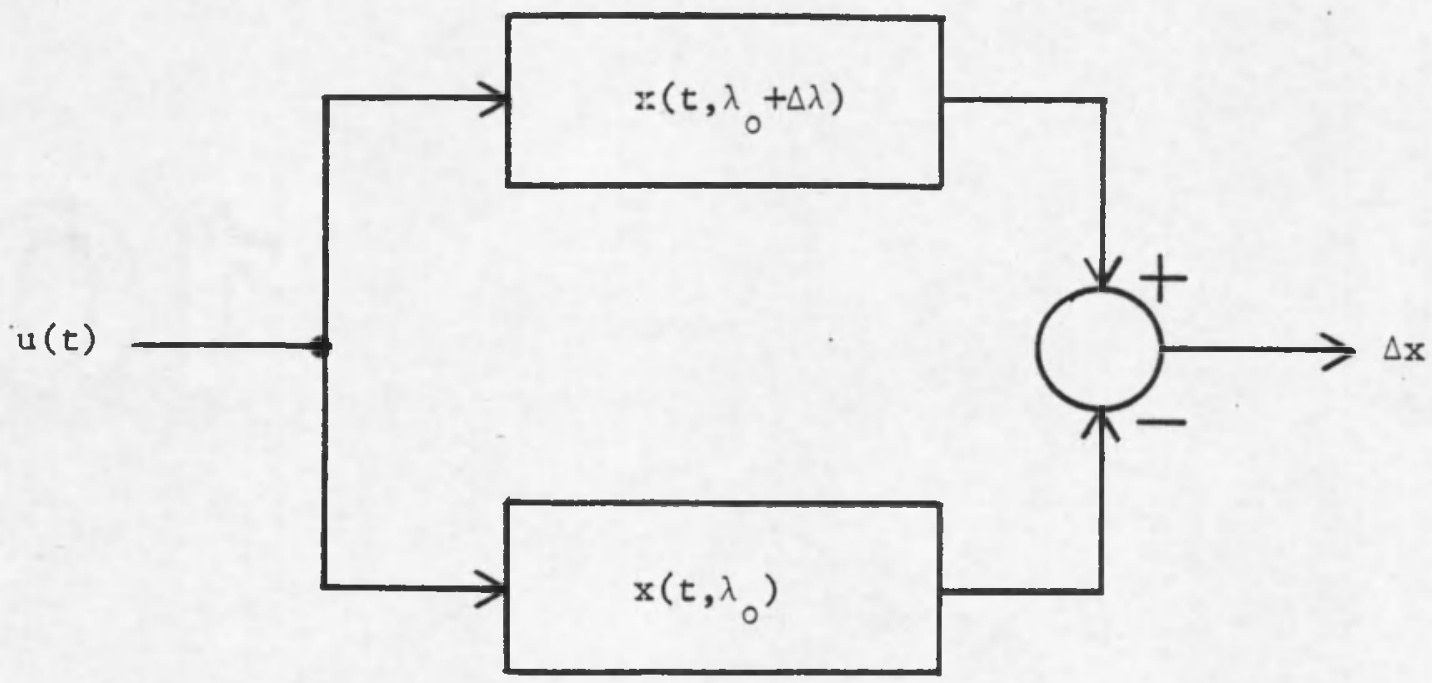

Figure 2-2 -- An Illustration of the Definition of the Sensitivity Function. 
As an example of how the sensitivity function was used in the CRBRP simulator, consider the open loop superheater model mentioned earlier. To utilize equation 2-4 on a digital computer the following finite difference approximation was used

$$
u_{\lambda_{i}}(t)=\frac{x_{i}\left(t, \lambda_{0}+\Delta \lambda\right)-x_{i}\left(t, \lambda_{0}\right)}{\Delta \lambda(\%)} ; i=1, n .
$$

The state variables in this model are the outlet sodium temperature, the tube wall temperature and the outlet superheated steam tempera ature. A $1 \%$ error from nominal was assumed in the sodium to tube wall heat transfer coefficient (HWA). The new tube wall to steam fouling resistance and tube wall temperature initial condition were then recalculated. These changes to the modified system were necessary to meet the design inlet and outlet superheater temperatures as outlined in the PSAR (see Section A-1 for details). A $20^{\circ} \mathrm{F}$ step in the sodium inlet temperature was then applied to both systems and the differences between both systems were noted. A similar procedure was then applied to the wall specific heat $\left(\mathrm{C}_{\mathrm{PWA}}\right)$. The sensitivity functions for the three state variables are plotted in Figure 2-3. From the figures it can be seen that a change in $\mathrm{H}_{W A}$ has a smaller effect than $\mathrm{C}_{\text {PWA }}$ for the state variables $T_{S C}$ and $T_{I C}$. However, $H_{W A}$ has a much greater effect on $\bar{T}_{W A}$ because of the change in the initial condition for $\bar{T}_{W A}$.

The sensitivity function plots have the desirable feature mentioned at the beginning of this chapter in that they are physically meaningful to the performance of the system. These plots are directly 

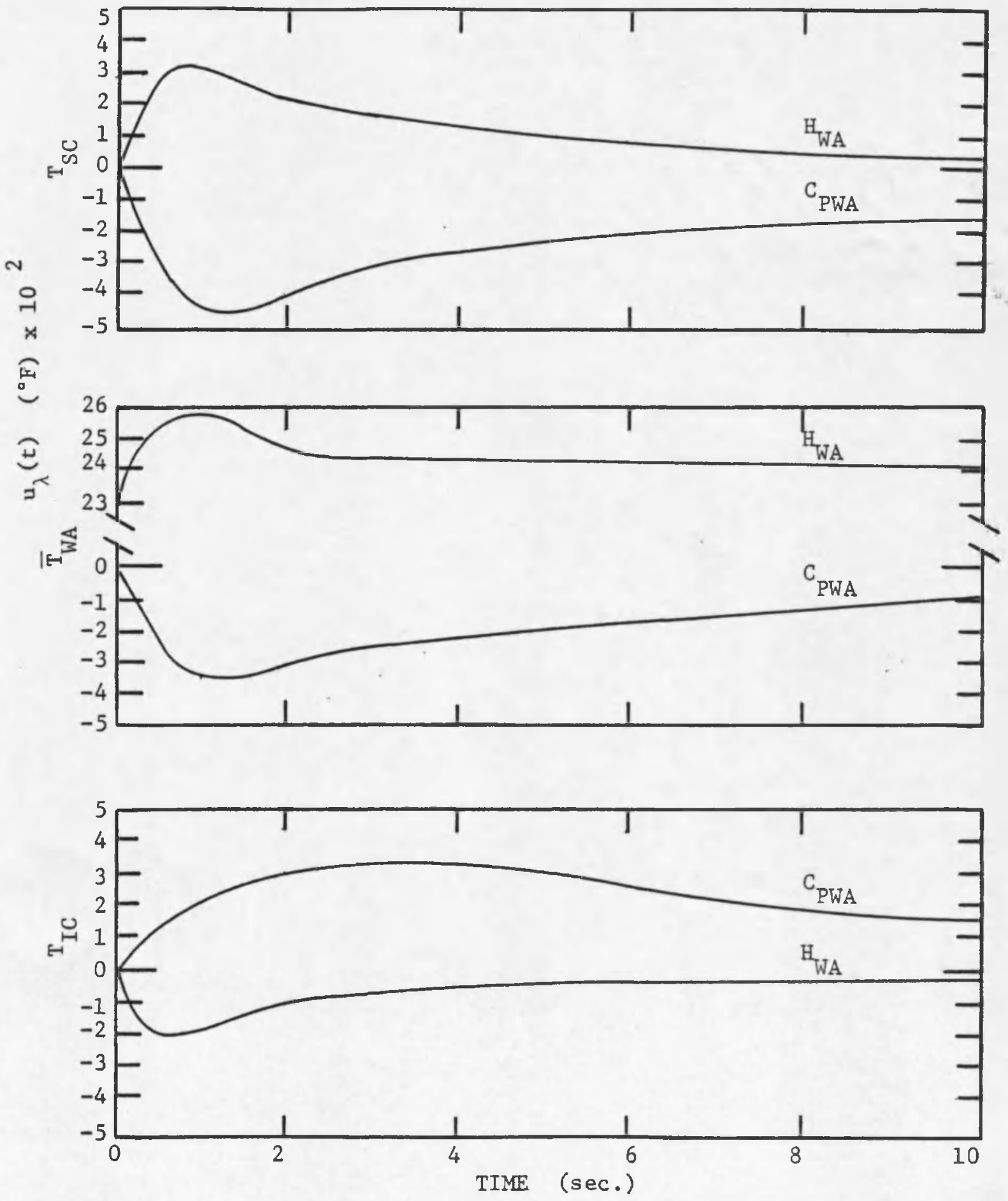

Figure 2-3 -- Time Domain Sensitivity of the 3rd Order Superheater Model Following a $20^{\circ} \mathrm{F}$ Step in the Sodium Inlet Temperature. 
related to the transient response and show just how much each part of the response is affected by the parameters.

This wealth of information is not in a compact form, however, since the sensitivity functions are time dependent. For purposes of comparison, it is convenient to have a sensitivity measure that yields a single real number. Previous authors have overcome this problem by adopting the following two sensitivity measures which utilize the time dependent sensitivity function plots.

The first measure is known as integral output sensitivity and is defined as

$$
\bar{u}_{\lambda}=\frac{1}{T} \int_{0}^{T} u_{\lambda}(t) d t
$$

where $T$ is a time interval large enough to allow $x(t)$ (the step response) to reach its final value. This measure, in effect, gives the average sensitivity over the time interval. The second measure is known as peak sensitivity and is defined as

$$
u_{\lambda}^{*}=u_{\lambda}(T)
$$

where $T$ is the time at which $\left|u_{\lambda}(t)\right|$ is a maximum. The conventence in using these two measures must be paid for by accepting the loss of information inherent in their use.

It was decided that the use of peak sensitivity was ideal for the type of parameter sensitivity study performed on this simulator. It is ideal because it not only yields a single number necessary for comparing a large number of parameters, but its very nature is safety oriented. 
From results obtained with its use the analyst can estimate which parameters are the most "safety sensitive." An added feature of its use is that this information can be used to put first order bounds on a transient due to parameter error. This feature is discussed in Section 3.4. Integral output sensitivity was abandoned because of the many extremely long simulation times required for the sensitivity function to reach its final value. Its measure was felt to be of much less importance for the type of safety related study conducted here. 
CHAPTER 3

\section{PARAMETER SENSITIVITY STUDY OF A CRBRP DYNAMIC SIMULATOR}

In this chapter the time domain sensitivity function discussed in Chapter 2 will be applied to the CRBRP dynamic simulator. To begin the discussion, a section will be devoted to the rationale behind the approach of the study. Following this, measures of parameter sensitivity with appropriate comments on reactor safety will be presented.

\subsection{Approach}

In the early phases of this work it became apparent that measures of parameter sensitivity could not be practically made by simulating the dynamics of the CRBRP as a whole. If this approach were to be taken, extremely long simulation times would be necessary for the effect of a parameter variation to be felt by all the state variables describing the plant. This is due to the large transport time delays in plant piping and large system time constants associated with the heat capacities of several of the plant components. The computer costs associated with such long simulations is a prohibiting factor because of the large number of parameters to be tested. To circumvent this problem the simulator was split into two sections.

The first section includes the equations describing the reactor, intermediate heat exchanger, and the fluid flow between them. Together they represent the primary loop of the CRBRP. A diagram of this portion of the plant can be found in Figure $3-1$. It can be noted from Figure $1-1$ 


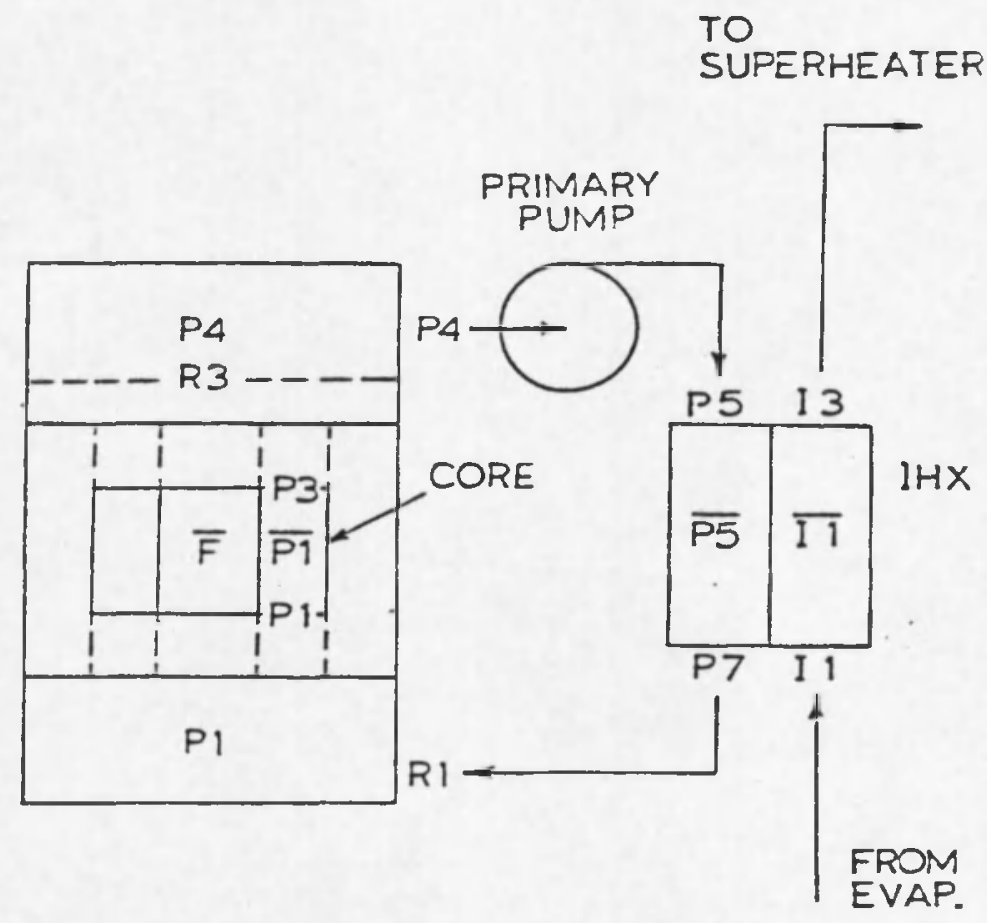

Pigure 3-1 -- Schematic Diagram of the Primary Loop. 
that the "cut" was made at the point of the largest transport time delay. By making the cut here, it was hoped that the major effects that parameter variations have on a transient initiated in the reactor would be felt by the state variables in the primary loop before any significant feedback effects could be felt from the intermediate loop. Ignoring these feedback effects is equivalent to asstming a constant inlet sodium temperature and flow rate at the inlet to the IHX on the intermediate side.

The second section includes the equations describing the steam generation system of the power plant, excluding the steam turbine and feedwater model. During the course of this study it was found that this latter section of the model exhibited unrealistic behavior when subjected to various transients. The major difficulty was the large magnitude of flow mismatch between the superheated steam flow to the turbine and the feedwater flow from the condenser. At steady state operating conditions these flows are equal. It would then be expected that for mild transients, the deviation from the steady state flow rates should be relatively small. The problem in the feedwater and turbine model is that it is over-simplified in that the explicit dynamics of such components as the condenser and feedwater heaters were not considered. The sensitivity study was therefore conducted on the open loop steam generator depicted in Figure 3-2. The open loop assumption is equivalent to setting the intermediate sodium, feedwater, and superheated steam flows, as well as the feedwater temperature, to constants. 
FROM IHX

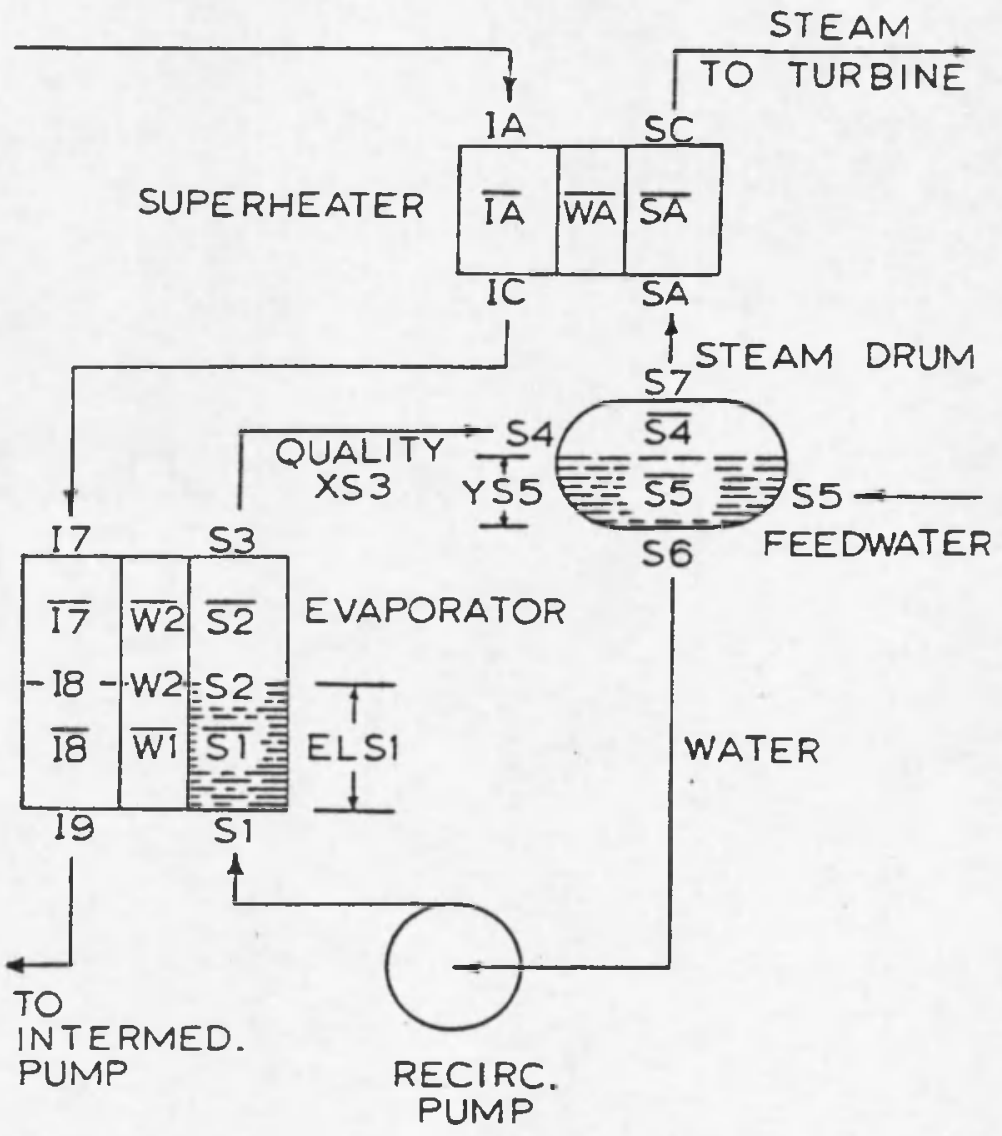

Figure 3-2 -- Schematic Diagram of the Open Loop Steam Generator. 
The magnitudes of the transients impressed on both sections were chosen to be small enough to allow the system of equations to exhibit an approximate linear behavior. In this way the superposition property of linear differential equations can be used to approximate the behavior of sensitivity functions for various magnitudes of the same type of transient (i.e., step).

As mentioned earlier the system of equations is nonlinear. Hence the sensitivity of a parameter is dependent on the operating point. Since the CRBRP simulator was intended to study transients in the 40-100\% power range, it would seem appropriate to study the sensitivity of parameters over this range. This was done in Section 3.2 .2 for the most sensitive parameters in the primary loop.

\subsection{Parameter Sensitivity in the Primary Loop}

\subsection{1 $100 \%$ Power Level}

The transient chosen to determine parameter sensitivity was a $10 c$ step in control rod reactivity. It was chosen because it approximates a realistic system transient and was mild enough for the system of equations to exhibit an approximate linear behavior.

By observing simulations of the total plant dynamics following the 10c step, it was noticed that significant feedback effects from the steam generation section to the intermediate sodium iniet of the IHX did not occur for 120 seconds. This was the simulation time chosen to stop the sensitivity runs in the primary loop. This cutoff time is also practical from a reactor safety standpoint in that it covers the first important minutes following transient initiation. 
The parameters chosen to be tested for sensitivity were those most susceptible to estimation error. Those are namely the nuclear and thermohydraulic properties of the system. A list of those tested is given in Table 3-1.

The following procedure was then employed to test for their sensitivity.

1. The parameter of interest was increased by $1 \%$.

2. Certain system equations were rebalanced, if necessary, to match the PSAR steady state design conditions at $100 \%$ power.

3. With the use of equation $(2-6)$ the model was similated at steady state for a significant time to check for noise in the sensitivity function due to rebalancing error.

4. The simulator was then run for 120 seconds following a $10 \mathrm{c}$ step in reactivity.

5. Magnitudes of the sensitivity function for the steady state and $10 \mathrm{c}$ step simulations were compared.

6. If the numerical value of the sensitivity function found in Step 4 was several orders of magnitude greater than that found in Step 3, then a good sensitivity measure had been determined. If this condition was not met, then step 2 was repated with greater accuracy. This was then followed by Steps $3,4,5$, and 6 .

7. Once a good sensitivity measure had been made, the time dependent sensitivity curves were observed for all the safety related state variables and the value of peak sensitivity was recorded. 
Table 3-1 List of Parameters in the Primary Loop.

Type

Name

Symbol

Nominal Value
Nuclear
Feedback
Coefficients
Doppler
$D C$
Axial Expansion
AXECC
$-0.0058$
Radial Expansion
RECC
SODDCC
$-0.023\left(\mathrm{c} /{ }^{\circ} \mathrm{F}\right)$
Sodium Density
$\beta_{1}$
Ist Group
$\beta_{2}$
3rd Group
4th Group
$B_{3}$
$\beta_{4}$
5 th Group
6th Group
$B_{5}$
$\beta_{6}$
$-0.21\left(\mathrm{c} /{ }^{\circ} \mathrm{F}\right)$
$-0.006\left(\mathrm{c} /{ }^{\circ} \mathrm{F}\right)$
Eractions
Delayed
Ist Group
Neutron
Time
Constants
2nd Group
3 rd Group
4th Group
5th Group
6th Group
$\lambda_{1}$
$\lambda_{2}$
$\lambda_{3}$
$\lambda_{4}$
$\lambda_{5}$
$\lambda_{6}$
0.00008254
0.00077560
0.00066600
0.00135400
0.00059080
0.00018100
Thermal
Properties of
Fuel Pin
Fuel Therm. Cond. AKF
Gap Conductance HDG
Fuel Specific Heat
Clad Therm. Cond.
${ }_{\mathrm{C}}^{\mathrm{PF}}$
$\mathrm{K}_{\mathrm{C}}$
$\mathrm{H}_{\mathrm{C}}$
$0.0129 \cdot\left(\sec ^{-1}\right)$
$0.0312 .\left(\mathrm{sec}^{-1}\right)$
$0.1330\left(\mathrm{sec}^{-1}\right)$
$0.3450\left(\mathrm{sec}^{-1}\right)$
$1.4100\left(\mathrm{sec}^{-1}\right)$
$1.4100\left(\mathrm{sec}^{-1}\right)$
$3.7500\left(\mathrm{sec}^{-1}\right)$
Sodium Film Cond.
FPGC
a
Fraction of Power
Generated in Core
Core
Fraction of Primary FFC
$784.4\left(\mathrm{Btu} /\left(\mathrm{hr} \mathrm{ft}^{2} \mathrm{~F}\right)\right)$
0.076 (Btu/(1bm $\left.\left.{ }^{\circ} \mathrm{F}\right)\right)$
13.4. (Btu/(hI ft $\left.{ }^{\circ} \mathrm{F}\right)$ )
a
Flow in Core
Primary Pump.
Efficiency
ETAPP
Inertia
AIPP
0.9239
Parameters
Heat Transfer
HNIP
0.80
IHX Thermal
Properties
Coefficient

a) See Shinaishin (1976) for equation used. 
A specific example as to how the above procedure was applied to the Doppler feedback coefficient can be found in Appendix B. This example also shows how the inclusion of the steam generator feedback affects the sensitivity function at 120 seconds.

Results of the sensitivity runs can be found in Table 3-2. This table lists the peak sensitivities of the temperature state variables located throughout the primary loop. Other state variables, describing the delayed neutron precursors, are not listed because they are not directly related to the safety of the system.

Entries signified by $\Delta$ indicate that the sensitivity function was non zero at the beginning of the simulation. This is caused, as mentioned in the superheater example of Chapter 2, by the needed change in initital conditions of these state variables to meet the PSAR design conditions.

Those results designated by an asterisk. $(*)$ are ones for which the sensitivity function was still increasing at the time of the cutoff. For these instances the value of the sensitivity function was taken at this time. This is due to the relative location of the parameter in the loop and how the parameter effects the time constants describing the dynamies of the loop. Generally, it can be noticed that most of these types of measures occur for parameters located in the reactor core model at the state variable locations $\mathrm{T}_{\mathrm{P} 7}, \mathrm{~T}_{\mathrm{I} 3}$, and $\mathrm{T}_{\mathrm{PI}}$. The main reason for this is that these locations are physically the most distant from the reactor core. This type of behavior can also be seen in other parameters in the 10op. One example of this is HNIP which is located in the 
Table 3-2 Peak Sensitivity Results from the Primary, Loop at 100\% Power Leve1.

$$
\left({ }^{\circ} \mathrm{F} \times 10^{2}\right)
$$

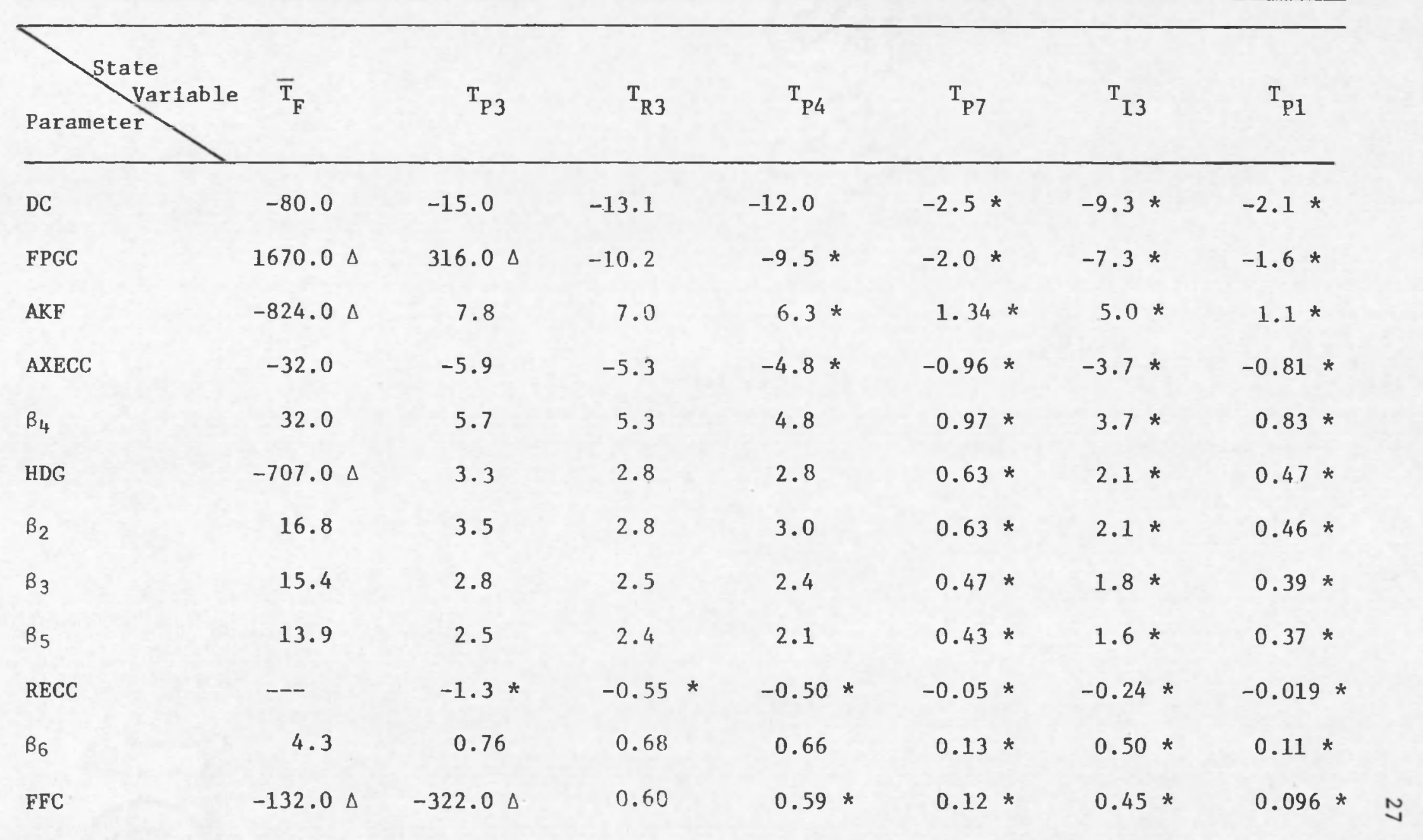




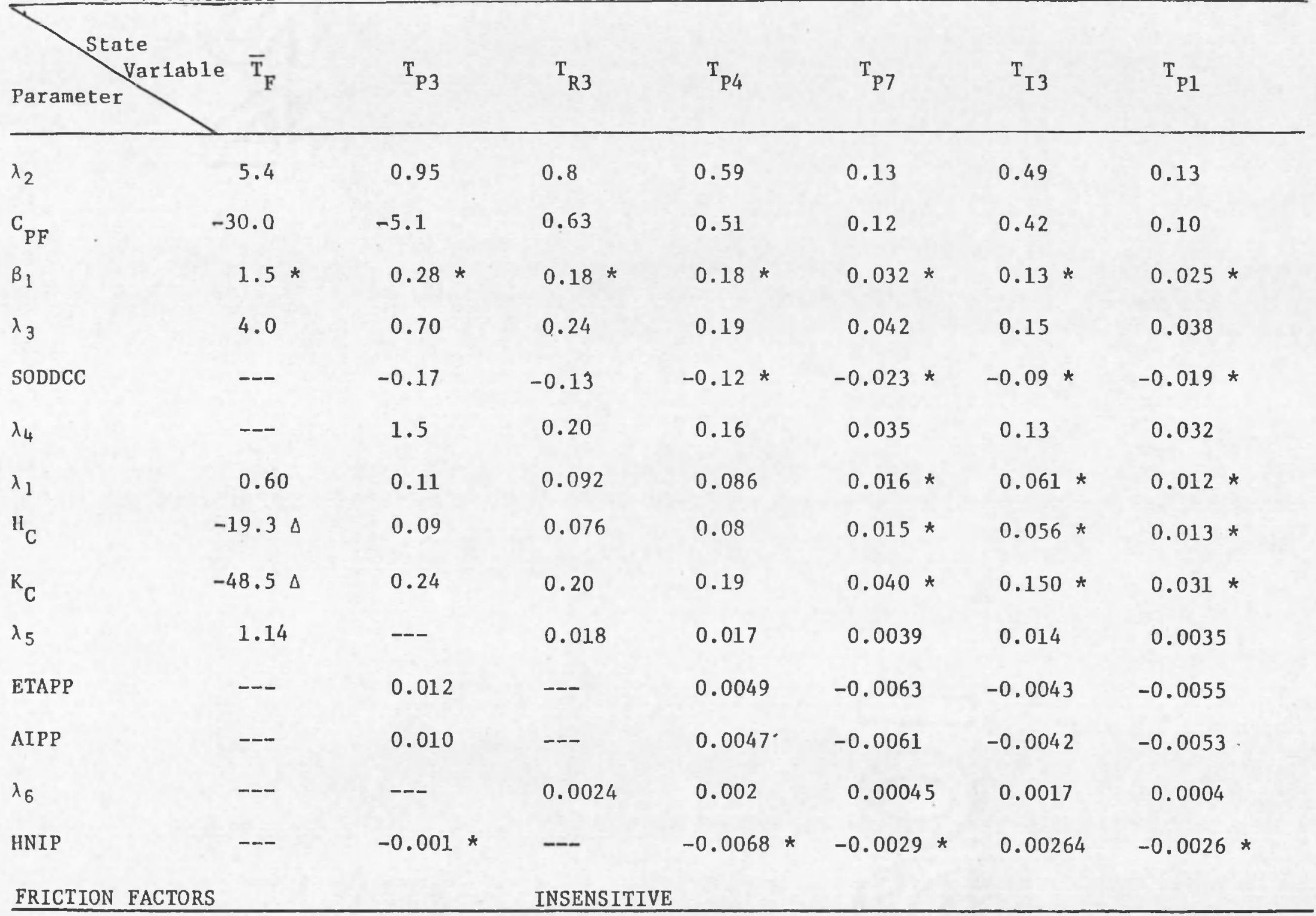


IHX. For this parameter the peak sensitivity first occurs at $\mathrm{T}_{\mathrm{I} 3}$ which is in the IHX. This is not the total picture, however, as can be seen by the sensitivities of the $\lambda^{\prime s}$. The first delayed neutron group decay constant, $\lambda_{1}$, has the longest half life of the six listed (53.72 sec.), whereas the other five range from 22.21 seconds to 0.18 seconds. It would therefore be expected that an error in a parameter associated with a long time constant would take longer to affect the transient than a short one. This is the case here since the sensitivity for $\lambda_{1}$ has not yet peaked at the cutoff time at locations $T_{P 7}, T_{I 3}$, and $T_{P 1}$, while those for $\lambda_{2}$ through $\lambda_{6}$ have done so.

It can also be noted from Table 3-2 that some of the parameters are listed as "insensitive." The reason for this is the way they are used in the equations of the model. The best explanation of this type of parameter is shown by an example (see Appendix C).

Table 3-3 gives the results of Table 3-2 normalized to the most "safety sensitive" parameter, namely the Doppler coefficient. It can be noted that the ratio of peak sensitivities for a given parameter in the core, relative to the Doppler coefficient, are approximately equal for all the state variable locations. Though the peaks generally occurred at different simulation times, these parameters represent a distinct class. The reason for this pattern is that each of these parameters directly affects the fuel temperature first. Once the difference in fuel temperature appears, this signal is filtered through the different differential equations describing the 1oop, affecting each subsequent state variable proportionately. A notable exception to this is the 
Table 3-3 The Absolute Value of the Peak Sensitivity Results Normalized to the Doppler Coefficient at 100\% Power Level in the Primary Loop.

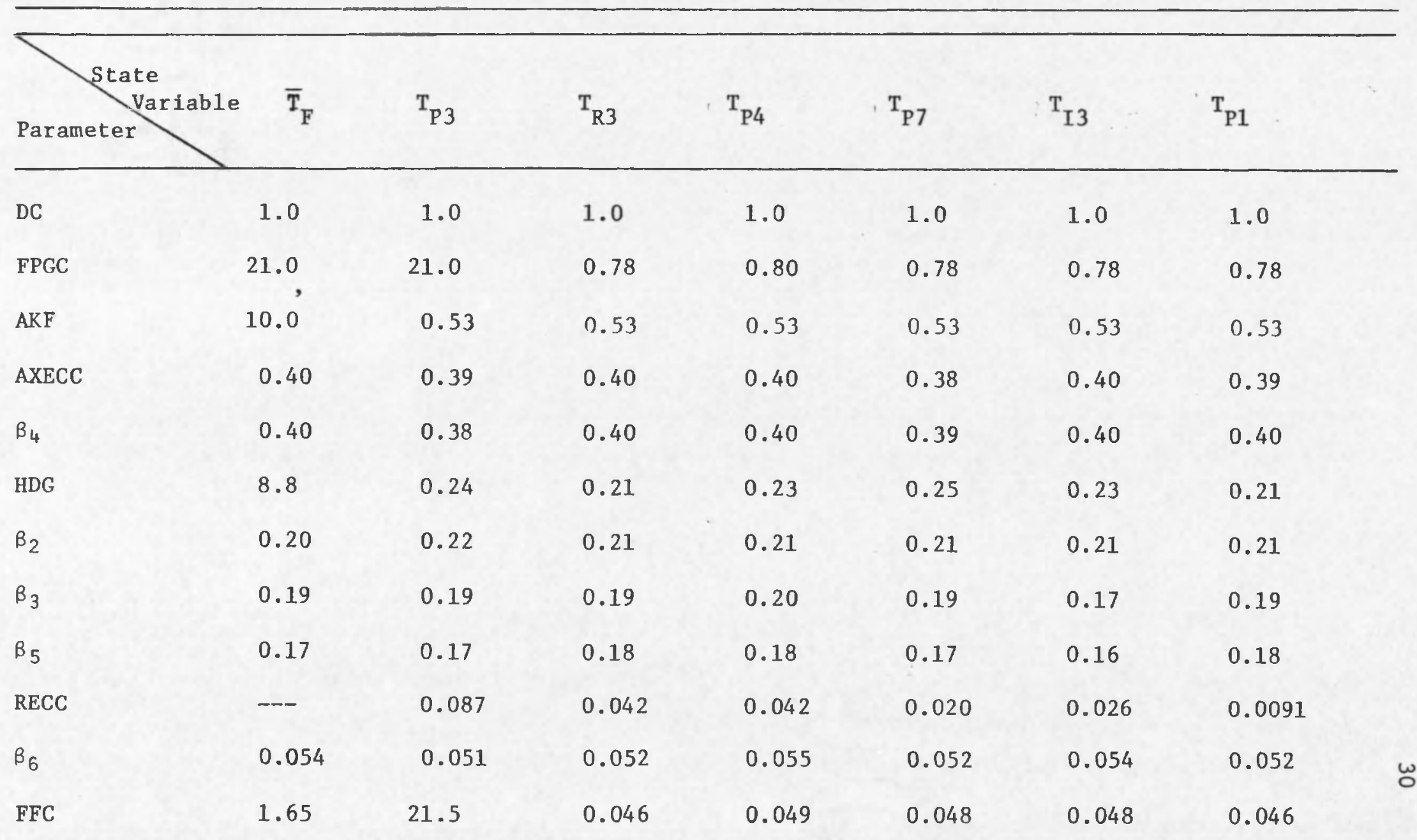


Table 3-3, Continued

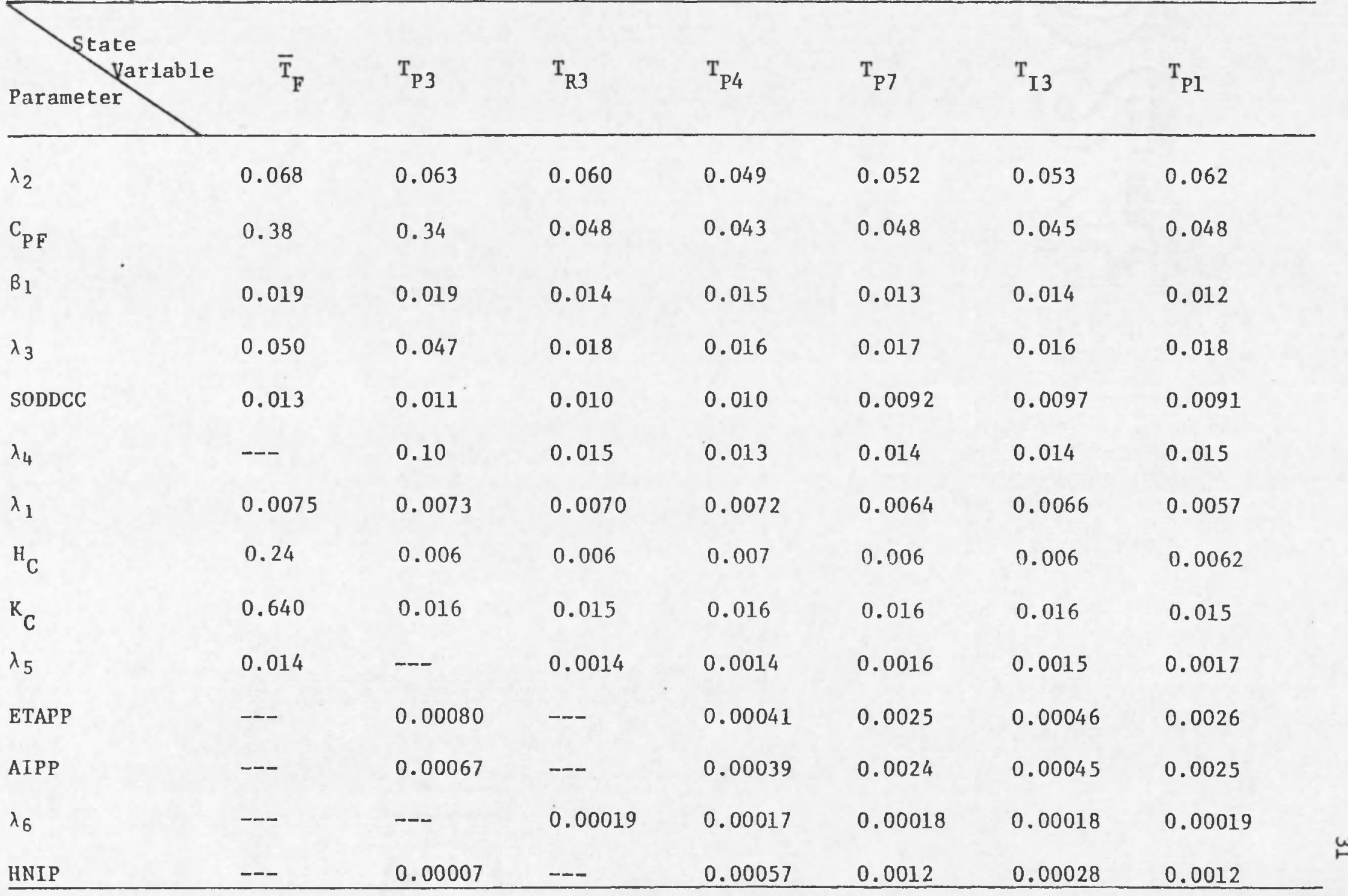


parameter RECC. The reason that its results do not exhibit the proportionality is because it is a long term feedback affect which depends on the inlet core temperature. The 120 second simulation cutoff was evidently not Iong enough for the sensitivity function, which was propagated from the fuel temperature first, to be transmitted around the 10op.

Another distinct class of parameters is represented by ETAPP and AIPP. It can be seen that their relative sensitivities are approximately equal but do not exhibit the same pattern as the core parameters.

In sumary, the first nine parameters in Table $3-3$ can be deemed sensitive enough to make them of primary concern when studying step reactivity transients. Special attention should be paid to those parameters which change the initial condition because this is where the major extremes occur. The parameters FFC, $\mathrm{KC}$ and $\mathrm{HC}$ should therefore be included in this "sensitive list." Table 3-2 is useful for putting approximate bounds on a particular step transient because it gives the actual magnitudes of the peak sensitivities due to parameter estimate error.

\subsection{2 $70 \%$ and $40 \%$ Power Levels}

In this section the peak sensitivities for the most important parameters of the previous section were recomputed at $70 \%$ and $40 \%$ of full power.

The procedure employed in obtaining them was essentially the same as the previous section except that the primary loop was rebalanced to meet the PSAR design conditions at these power levels. These design conditions are given in Table 3-4. In order to meet these design conditions it should be noted that the heat transfer fouling resistance term 
Table 3-4 PSAR Design Conditions at 40\% and $70 \%$ Power Level.

\begin{tabular}{|c|c|c|}
\hline State Variable & 40\% Power & $70 \%$ Power \\
\hline $\mathrm{T}_{\mathrm{P} 1}$ & $685^{\circ} \mathrm{F}$ & $704^{\circ} \mathrm{F}$ \\
\hline $\mathrm{T}_{\mathrm{P7}}$ & $685^{\circ} \mathrm{F}$ & $704^{\circ} \mathrm{F}$ \\
\hline $\mathrm{T}_{\mathrm{P} 4}$ & $949^{\circ} \mathrm{F}$ & $969^{\circ} \mathrm{F}$ \\
\hline $\mathrm{T}_{I I}$ & $604^{\circ} \mathrm{F}$ & $620^{\circ} \mathrm{F}$ \\
\hline $\mathrm{T}_{\text {I3 }}$ & $916^{\circ} \mathrm{F}$ & $922^{\circ} \mathrm{F}$ \\
\hline Primary Flow Rate & $4611 \mathrm{lbm} / \mathrm{sec}$ & $8056 \mathrm{Ibm} / \mathrm{sec}$ \\
\hline Intermediate Flow Rate & $3880 \mathrm{Ibm} / \mathrm{sec}$ & $7028 \mathrm{Ibm} / \mathrm{sec}$ \\
\hline Primary Pump Speed & 457 RPM & 777 RPM \\
\hline
\end{tabular}


In the IHX had to be adjusted. Since the author of the simulator assumed this to be constant throughout the $40-100 \%$ power range, this is a problem which should be dealt with in future work on this project.

From Table 3-4 it can be noted that the primary and secondary sodium flow rates are considerably lower than those at $100 \%$ power. Therefore, the delay times in the piping of the plant and the cut off time at which to stop the sensitivity runs will be longer. These cutoff times were estimated in accordance with the procedures outlined in Appendix D. These estimations were found to be 180 seconds at $70 \%$ power and 330 seconds at $40 \%$ power.

The results at these power levels can be found in Table 3-5 and 3-6. By comparing Tables $3-2,3-3$, and $3-6$, it can be noted that both the magnitude and relative peak sensitivities change as a function of power level. This, as mentioned earlier, is due to the nonlinear nature of the system of equations. Figures $3-3$ and $3-4$ show plots of the absolute value of the peak sensitivity magnitudes in the $40-100 \%$ power range for the state variables $\overline{\mathrm{T}}_{F}$ and $\mathrm{T}_{P 4}$.

\subsection{Parameter Sensitivity in the Open Loop Steam Generator}

The transient chosen for this section of the plant was a $20^{\circ} \mathrm{F}$ step in superheater inlet sodium temperature.

Parameters to be tested for sensitivity are those listed in Table 3-7.

The cut-off time was chosen to be 100 seconds. This value was estimated by observing the sensitivity runs and noting when significant feedback effects occurred. 


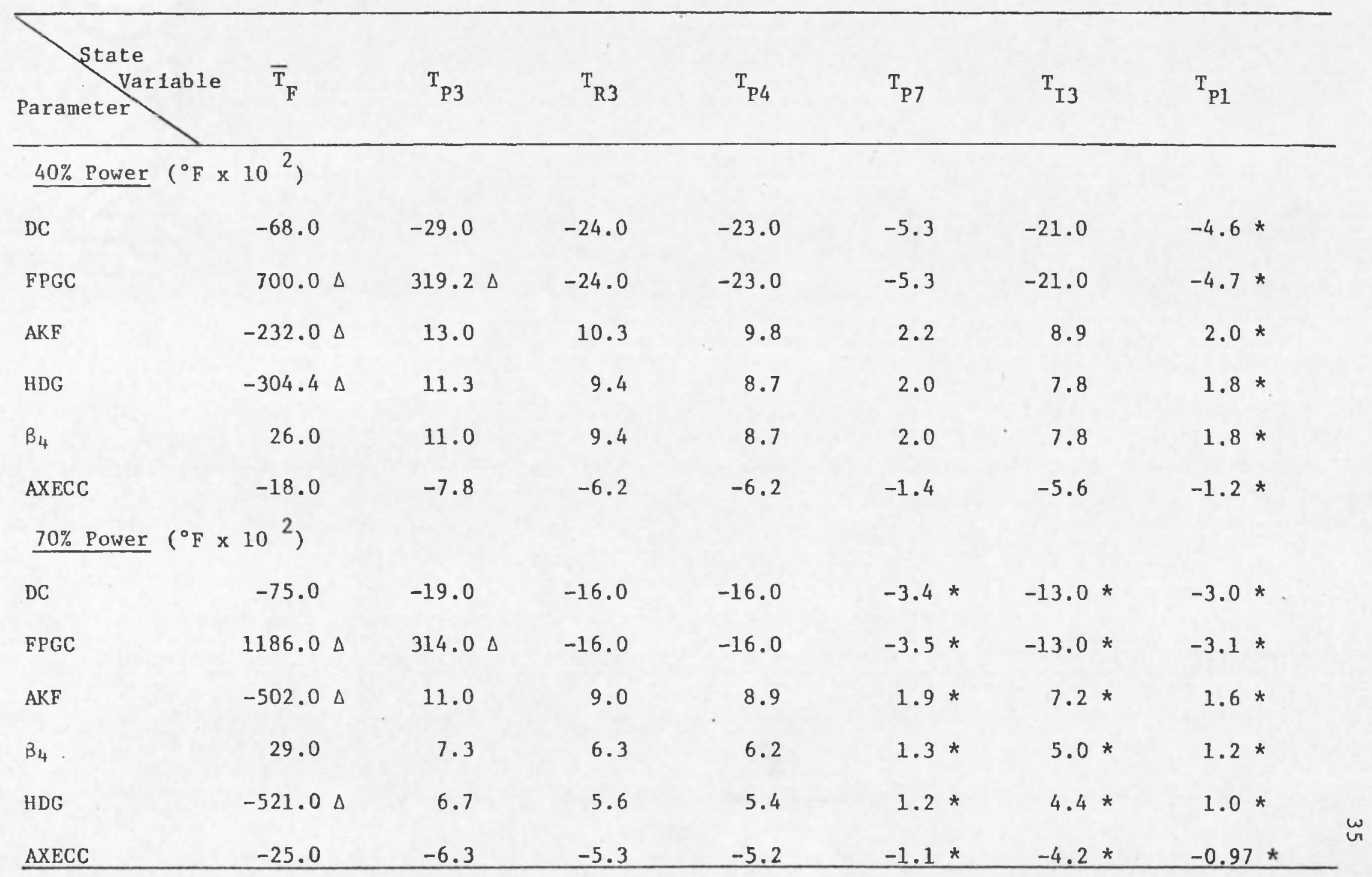


Table 3-6 The Absolute Value of the Peak Sensitivity Results Normalized to the Doppler Coefficient at $40 \%$ and $70 \%$ Power Level in the Primary Loop.

\begin{tabular}{lcccccc}
\hline & & & & & \\
\hline \\
\hline Parameter
\end{tabular}




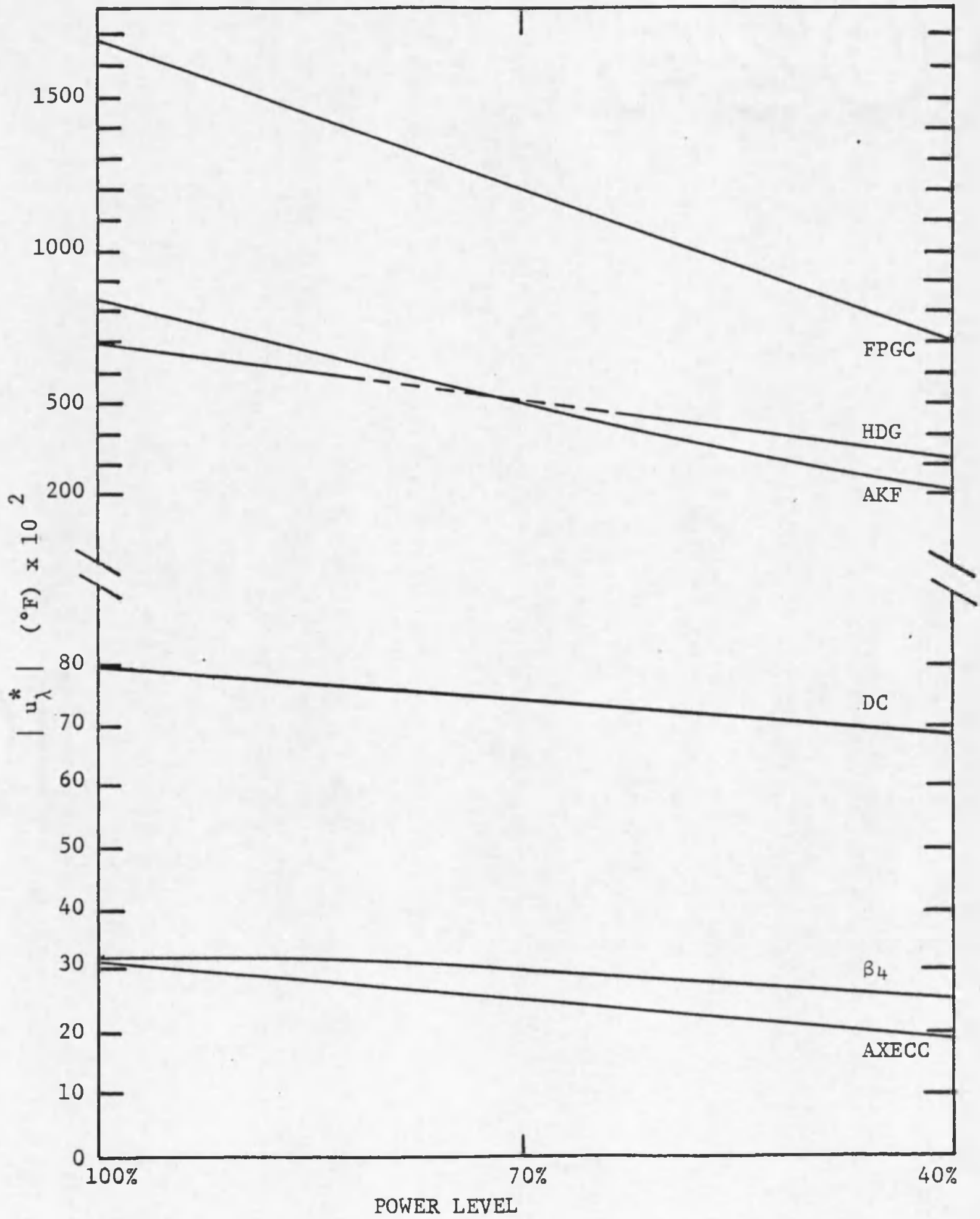

Figure 3-3 -- The Absolute Value of the Fuel Temperature Peak Sensitivity in the $40-100 \%$ Power Range. 


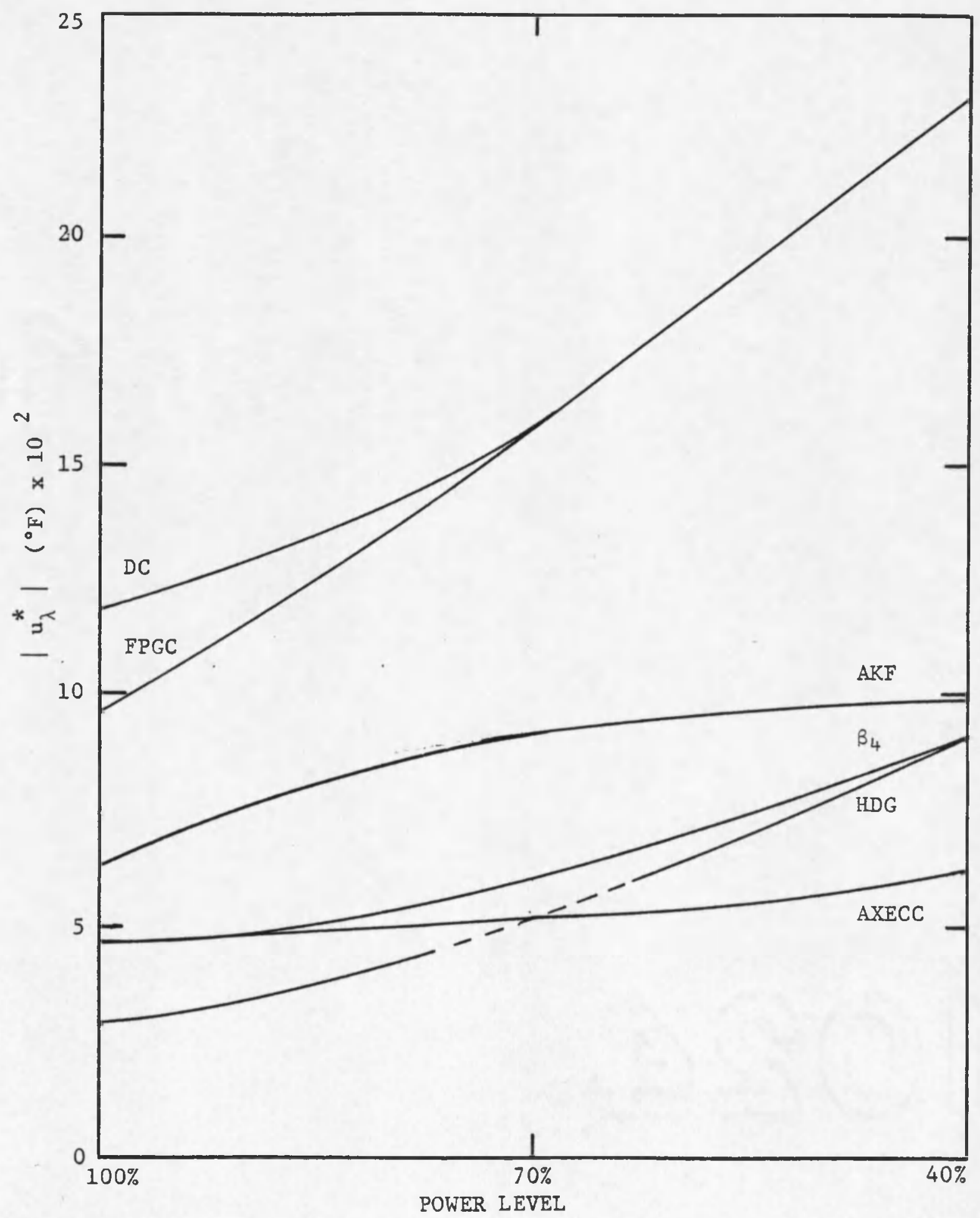

Figure 3-4 -- The Absolute Value of the Reactor Exit Temperature Peak Sensitivity in the 40-100\% Power Range. 
Table 3-7 List of Parameters in the Steam Generator.

Type Name Symbol Nominal Value

\section{Heat}

Transfer

Coefficients

Tube Wall

Specific Heats

Tube Wall

Thermal

Conductivities

Friction Factors

Slip Ratio
Sodium to Wall

in Superheater

Wall to Water

in Evaporator

Sodium to Wall

in Evaporator

Specific Heat in Superheater

Specific Heat

in Evaporator

Thermal Conducti-

vity in Superheater

Thermal Conducti-

vity in Evaporator

$\begin{array}{ll}\mathrm{H}_{\mathrm{NS}} \\ { }_{\mathrm{WE}}^{\mathrm{H}_{\mathrm{NE}}} & \mathrm{a}\end{array}$

$C_{\text {PWA }}$

$0.12\left(\mathrm{Btu} / 1 \mathrm{bm}-{ }^{\circ} \mathrm{F}\right)$

$C_{\text {PWE }}$

$0.12\left(\mathrm{Btu} / 1 \mathrm{bm}-{ }^{\circ} \mathrm{F}\right)$

K WA

$22.0\left(\mathrm{Btu} / \mathrm{hr}-\mathrm{ft}-{ }^{\circ} \mathrm{F}\right)$

$K_{Y \sqrt{E}}$

$22.0\left(B t u / h r-f t-{ }^{\circ} F\right)$
Two Phase Flow

Friction Multiplier

Evaporator Friction

Factor

Evaporator Friction

Factor

Slip Ratio in

Evaporator
$R D$

$F_{S 1 A}$

$F_{S 2 A}$

$S R$

1.00

a) See Shinaishin (1976) for equation used. 
The procedure employed was that outlined in Section 3.2 .1 as applied to the steam generator section of the plant.

Results of the sensitivity runs can be found in Tables $3-8$ and 3-9. Table 3-8 gives the magnitudes of the peak sensitivities while Table 3-9 gives the relative sensitivities. From Table 3-8 it can be seen that, in general, the most sensitive parameters by component model are $C_{P W A}$ in the superheater, $H_{W E}$ and $C_{P W E}$ in the evaporator, and $R D$ and $\mathrm{F}_{\mathrm{S} 2 \mathrm{~A}}$ which appear in the evaporator-steam drum loop momentum equations. As stated earlier, special attention should be paid to those parameters which affect the initial conditions of certain state variables. By looking at the relative sensitivities in Table 3-8, one can determine which parameters are the most important in terms of their overall influence on the steam generator dynamics. It will be noticed that $C_{\text {PWA }}$ affects the superheater state variables the most, while $R D$ and $F_{S 2 A}$ are the most important in their effects on the evaporator and steam drum loop state variables.

\subsection{A Method for Putting First Order Bounds on Simulation Transients}

The results of the previous three sections can be used to put approximate bounds on the transients studied in the primary loop and steam generator. This can be done in the following way.

The Taylor series expansion, equation (2-4), written for more than one parameter is

$$
x(t)=x_{0}(t)+\sum_{i=1}^{n} \frac{\partial x}{\partial \lambda_{i}}(t) \Delta \lambda_{i}+\sum_{i=1}^{n} \sum_{j=1}^{n} \frac{\partial^{2} x}{\partial \lambda_{i} \partial \lambda_{j}}(t) \Delta \lambda_{i} \Delta \lambda_{j}+\ldots
$$


Table 3-8 Peak Sensitivity Results from the Open Loop Steam Generator.

$$
\left(\times 10^{2}\right)
$$

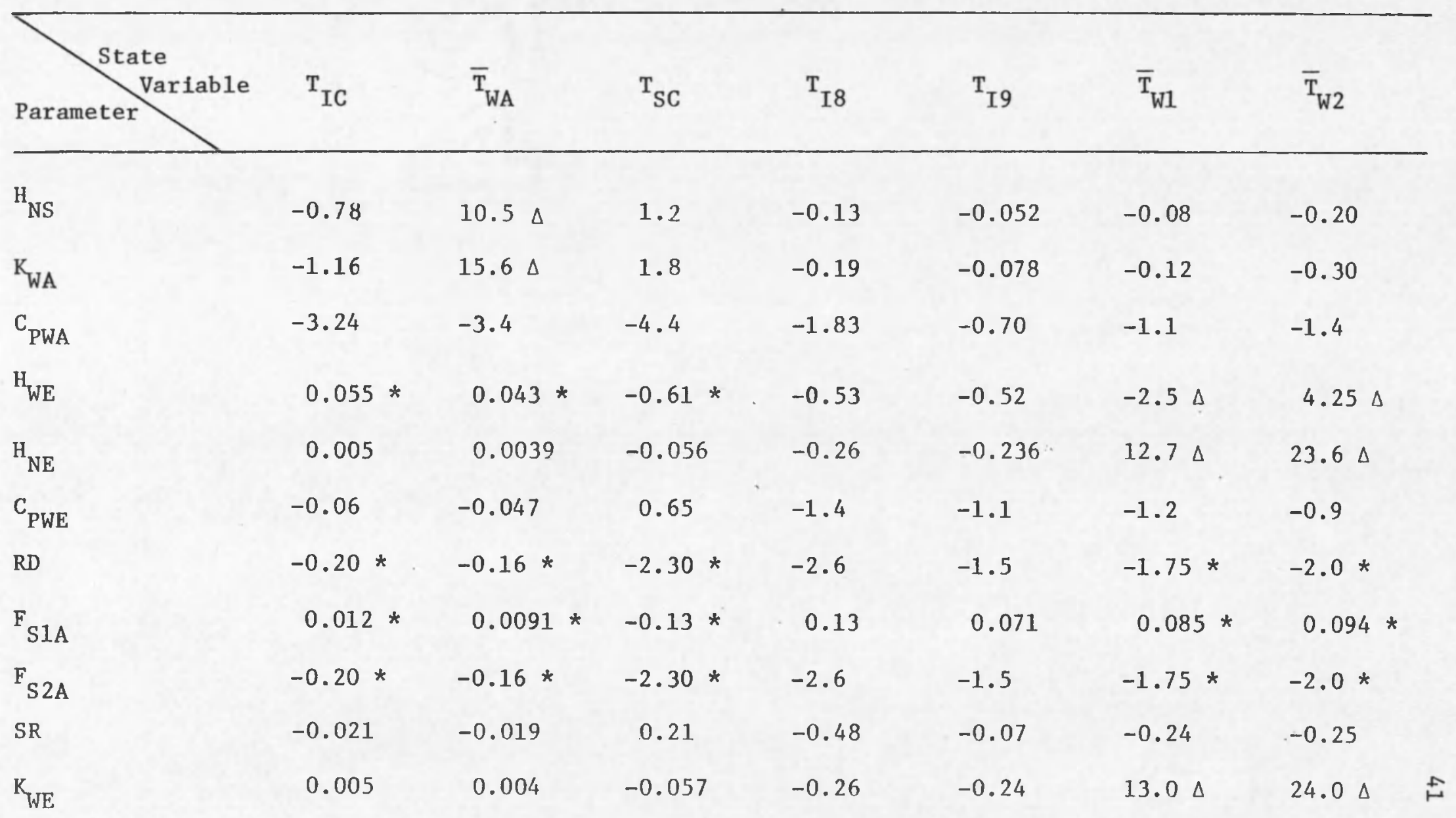


Tab1e 3-8, Continued

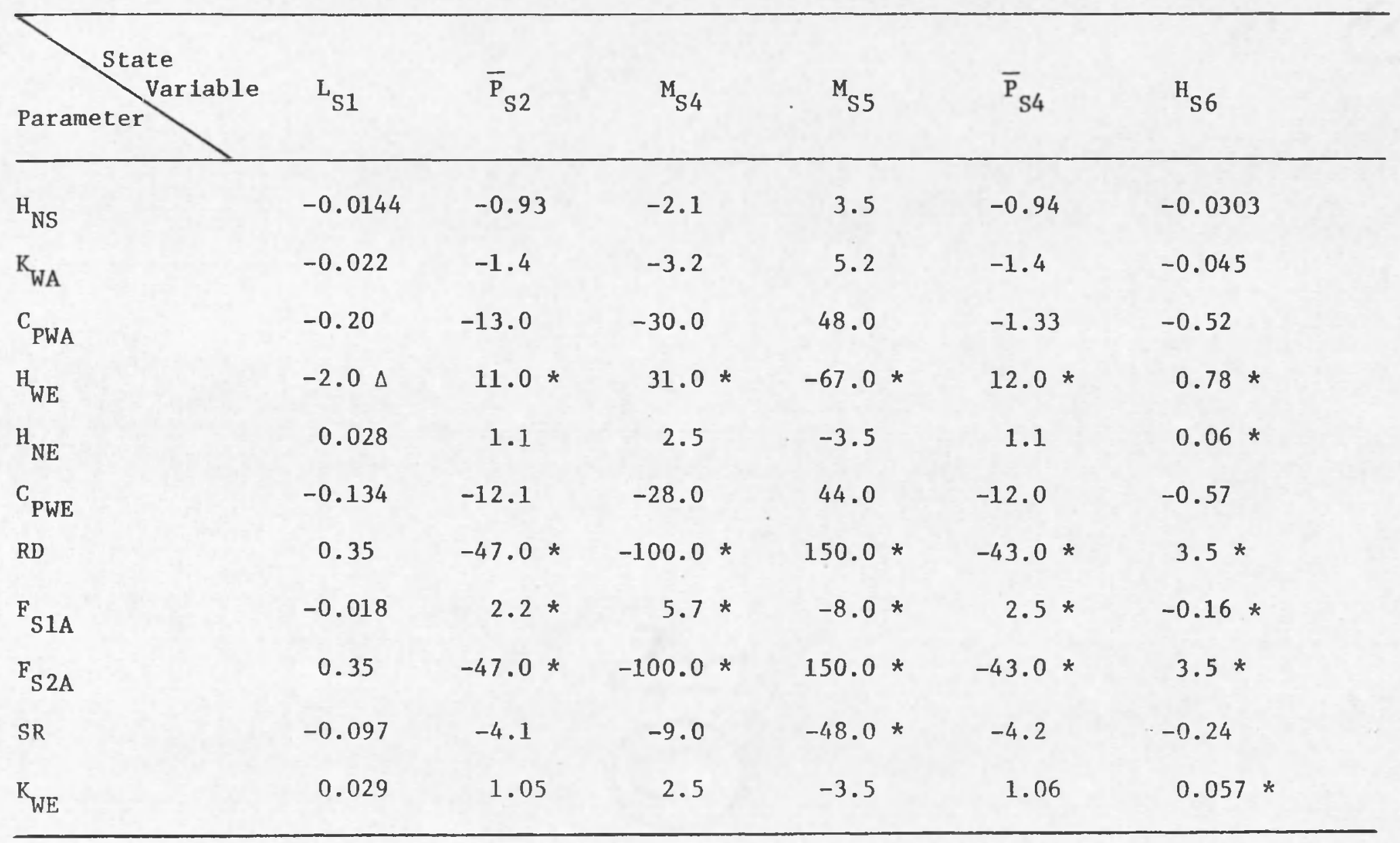


Table 3-9 The Absolute Value of the Peak Sensitivity Results Normalized to the Most Sensitive Parameters in the Steam Generator.

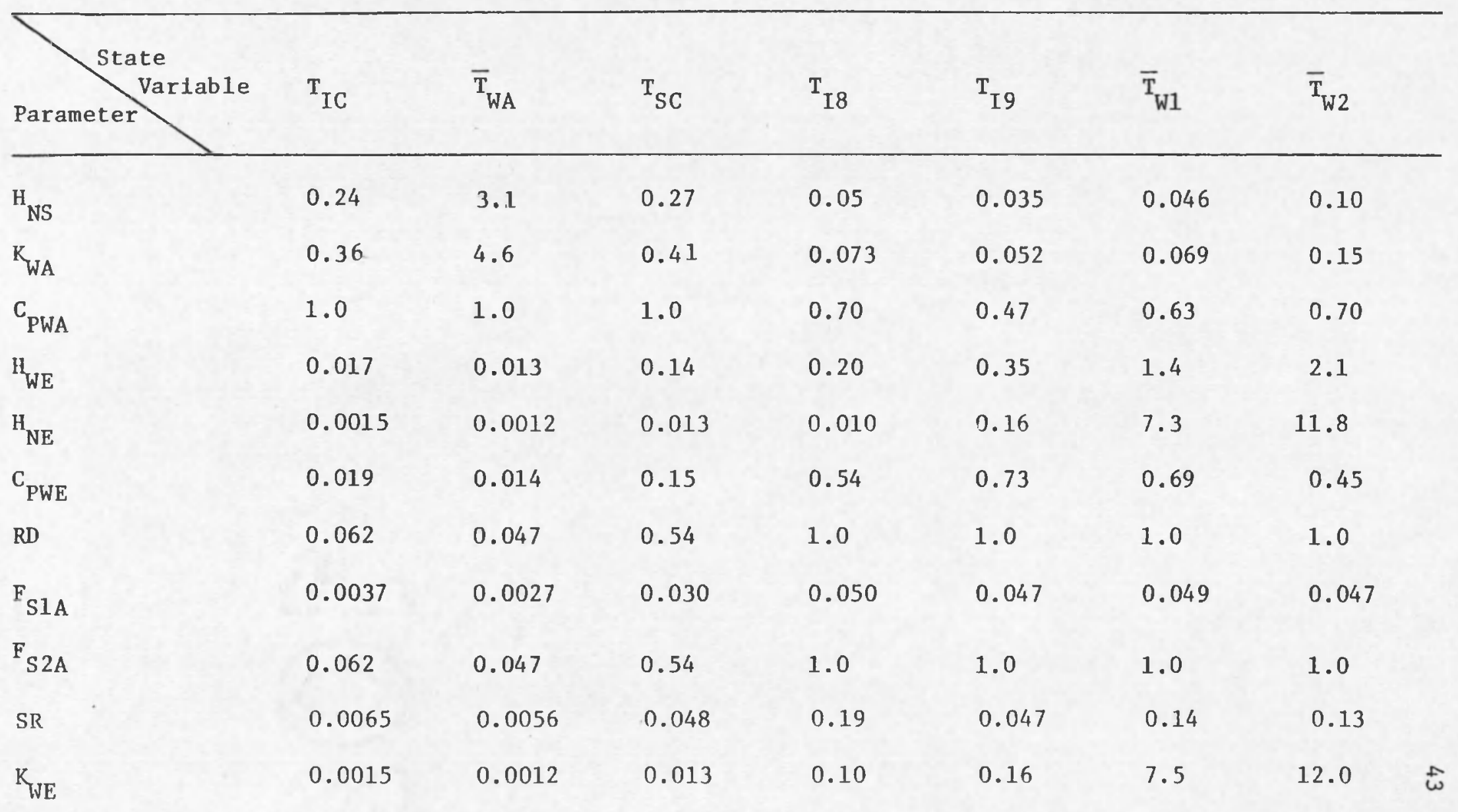


Tab1e 3-9, Continued

\begin{tabular}{|c|c|c|c|c|c|c|}
\hline Parate & $\overline{\mathrm{L}}_{\mathrm{S} 1}$ & $\overline{\mathrm{P}}_{\mathrm{S} 2}$ & $\mathrm{M}_{\mathrm{S} 4}$ & $M_{S 5}$ & $\overline{\mathrm{P}}_{\mathrm{S} 4}$ & $\mathrm{H}_{\mathrm{S} 6}$ \\
\hline $\mathrm{H}_{\mathrm{NS}}$ & 0.041 & 0.020 & 0.021 & 0.023 & 0.022 & 0.0087 \\
\hline $\mathrm{K}_{\mathrm{WA}}$ & 0.063 & 0.030 & 0.032 & 0.035 & 0.033 & 0.013 \\
\hline $\mathrm{C}_{\text {PWA }}$ & 0.57 & 0.28 & 0.30 & 0.32 & 0.031 & 0.15 \\
\hline $\mathrm{H}_{\mathrm{WE}}$ & 5.7 & 0.23 & 0.31 & 0.45 & 0.28 & 0.22 \\
\hline${ }^{\mathrm{H}}{ }_{\mathrm{NE}}$ & 0.08 & 0.024 & 0.025 & 0.024 & 0.026 & 0.017 \\
\hline${ }_{\text {PWE }}$ & 0.38 & 0.26 & 0.28 & 0.29 & 0.28 & 0.16 \\
\hline $\mathrm{RD}$ & 1.0 & 1.0 & 1.0 & 1.0 & 1.0 & 1.0 \\
\hline $\mathrm{F}_{\mathrm{S} 1 \mathrm{~A}}$ & 0.051 & 0.047 & 0.057 & 0.053 & 0.058 & 0.046 \\
\hline $\mathrm{F}_{\mathrm{S} 2 \mathrm{~A}}$ & 1.0 & 1.0 & 1.0 & 1.0 & 1.0 & 1.0 \\
\hline SR & 0.28 & 0.087 & 0.090 & 0.32 & 0.098 & 0.069 \\
\hline $\mathrm{K}_{\mathrm{WE}}$ & 0.083 & 0.023 & 0.025 & 0.0233 & 0.025 & 0.016 \\
\hline
\end{tabular}


If $t$ is chosen at the time of the peak sensitivity, and assuming that all peaks occur at the same time $\tau$, the first order terms can be rewritten

$$
x(\tau)-x_{0}(\tau) \simeq \sum_{i=1}^{n} \frac{\partial x}{\partial \lambda_{i}}(\tau) \Delta \lambda_{i}
$$

To put this equation in a form useful for bounding transients we write

$$
\varepsilon_{s v} \simeq \sum_{i=1}^{\mathrm{n}}\left|\mathrm{u}_{\lambda_{i}}^{*}\right| \quad \mathrm{T}_{\lambda_{i}}
$$

where

$\varepsilon_{\text {sv }} \equiv$ approximate bounding tolerance on the response of a particular state variable

$\left|u_{\lambda_{i}}^{*}\right| \equiv$ absolute value of the peak sensitivity for the parameter $\lambda_{i}$

${ }^{T} \lambda_{1} \equiv$ relative tolerance of parameter expressed in percent

As discussed earlier, the peak sensitivities do not generally occur at the same time; assuming they do is definitely on the conservative side. This conservatism is most acceptable when juding reactor safety.

An example of how equation (3-2) was applied can be found in Appendix E. 
CHAPTER 4

\section{CONCLUSIONS AND RECOMMENDATIONS}

\subsection{Conclusions}

In this thesis the use of peak sensitivity was found to be ideal in determining the most "safety sensitive" parameters in a system model. Through its use the most important parameters in the CRBRP dynamic simulator were identified for the type of step transients considered.

From the results obtained in the primary loop section of the plant, it was found for step reactivity transients that the parameters which directly affected the fuel temperature were the most sensitive. Of these the Doppler feedback coefficient and the fraction of power generated in the core were generally the most important parameters in the 40-100\% power range. Other important parameters include the fuel thermal conductivity, axial expansion feedback coefficient, gap conductance, the fraction of flow in the core, clad thermal conductivity, fuel specific heat and the second through fifth delayed neutron fractions. Results obtained from the steam generator revealed which parameters should be given special attention and how they affect different components of the model. Important parameters here include the two phase flow friction.multiplier, superheater and evaporator.wall specific heats and several parameters which affected the initial condition of a safety related state variable. 
Another advantage of using peak sensitivity is that approximate bounds can be put on a transient due to parameter estimate error. This is very useful from a reactor safety standpoint.

\subsection{Recommendations}

As stated in Chapter 2, the sensitivity function is dependent on on the type of transient initiator. The step in reactivity was chosen because it approximates a transient expected under normal power plant operation. (Sensitivity runs conduced on terminated ramp inputs spread over 10 seconds showed results very similar to those for the step.) A load perturbation transient would also be expected under normal operation. Once the problem in the turbine-feedwater model has been rectified, a sensitivity analysis for this type of perturbation should be conducted.

It has been discussed that in order to determine parameter sensitivity of the CRBRP simulator in a practical fashion the simulator was split into two sections. These sections were the primary loop and steam generation system respectively. Because of this split it was not possible to test how a parameter located in the primary loop affected the dynamics of the steam generator and vice versa. As soon as the computer costs associated with the testing the whole CRBRP simulator are reduced, this type of study should be conducted.

It has been shown that approximate bounds can be put on the transients studied. This was done without further use of the computer. If warranted, a more accurate determination of these bounds can be made by further computer simulations where only the more sensitive parameters need be considered (see Section A.5). 
Future work to be conducted on the CRBRP dynamic simulator includes the analysis of the existing automatic controllers to insure adequate stability margins. The results of this study should be taken into consideration such that the stability of the controllers will not be affected appreciably due to parameter estimate error. Future work will undoubtedly include the upgrading and refinement of the existing .plant models. When such changes are made sensitivity studies should be conducted and compared with the results of this thesis. 
APPENDIX A

PROCEDURE FOR MEETING PSAR DESIGN CONDITIONS

IN THE SUPERHEATER EXAMPLE

The following procedure is necessary to meet the design inlet and outlet superheater temperatures following a one percent change in a parameter from nominal.

From Figure 1-1 the design inlet and outlet temperatures are

Sodium Side

Superheater Inlet

$\mathrm{T}_{\text {IA }}=936 \mathrm{~F}^{\circ}$

Superheater Outlet

$T_{I C}=855 \mathrm{~F}^{\circ}$

$W_{I}=3.834 \times 10^{7} 1 \mathrm{bm} / \mathrm{hr}$

Superheater Flow Rate

Steam Side

$$
\mathrm{T}_{\mathrm{SA}}=615.2^{\circ} \mathrm{F}
$$$$
\mathrm{T}_{\mathrm{SC}}=905 \mathrm{~F}^{\circ}
$$

The differential equations representing the energy balances in each of the three radial regions are:

I. Sodium Side

$$
\frac{d T_{I C}}{d t}=\frac{1}{C_{P I A} V_{I A} \bar{P}_{I A}}\left[C_{P I A} W_{I A}\left(T_{I A}-T_{I C}\right)-H_{W A}\left(\bar{T}_{I A}-\bar{T}_{W A}\right)\right] \quad(A-1)
$$

II. Tube Wall

$$
\frac{d T_{W A}}{d t}=\frac{1}{C_{P W A}{ }^{M} W A}\left[H_{W A}\left(\bar{T}_{I A}-\bar{T}_{W A}\right)-H_{S S A}\left(\bar{T}_{W A}-\bar{T}_{S A}\right)\right]
$$


III. Steam Side

$$
\frac{d \mathrm{~T}_{S C}}{\mathrm{dt}}=\left(\frac{1}{\mathrm{C}_{\mathrm{PS} \mathrm{V}_{\mathrm{SA}} \bar{\rho}_{S A}}}\right)\left[\mathrm{H}_{S S A}\left(\overline{\mathrm{T}}_{\mathrm{WA}}-\overline{\mathrm{T}}_{S A}\right)-\mathrm{w}_{S A}\left(\mathrm{~h}_{S C}-\mathrm{h}_{S A}\right)\right]
$$

where

$$
\begin{aligned}
& \mathrm{C}_{\mathrm{P}} \quad \equiv \text { specific heat of region } \\
& \mathrm{V} \quad \equiv \text { volume of region } \\
& \mathrm{M} \quad \equiv \text { mass of region } \\
& \mathrm{W}_{\mathrm{N}} \quad \equiv \text { enthalpy at node } \mathrm{N} \\
& \mathrm{W}_{\mathrm{IA}} \equiv \text { intermediate flow rate } \\
& \mathrm{W}_{\mathrm{SA}} \quad \equiv \text { superheated steam flow rate } \\
& \mathrm{T}_{\mathrm{N}} \quad \equiv \text { temperature at node } \mathrm{N} \\
& \mathrm{H}_{\mathrm{WA}} \equiv \text { sodium to tube mid wall heat transfer coefficient } \\
& \mathrm{H}_{\mathrm{SSA}} \equiv \begin{array}{l}
\text { tube mid wall to superheated steam heat transfer } \\
\text { coefficient }
\end{array}
\end{aligned}
$$

\section{A.1 $\mathrm{H}_{\mathrm{WA}}$ Sensitivity}

The nominal value of $\mathrm{H}_{\mathrm{WA}}$ at steady state and with a constant sodium flow rate is $40267846.8 \mathrm{Btu} / \mathrm{hr} / \mathrm{F}^{\circ} .^{1}$ From this value one finds that $\overline{\mathrm{T}}_{\mathrm{WA}}=872.253 \mathrm{~F}^{\circ}$ and $\mathrm{H}_{\mathrm{SSA}}=8345829.46 \mathrm{Btu} / \mathrm{hr} / \mathrm{F}^{\circ}$. Increasing $\mathrm{H}_{\mathrm{WA}}$ by one percent ylelds $40670525.2 \mathrm{Btu} / \mathrm{hr} / \mathrm{F}^{\circ}$. At steady state set

1. Nine significant figures were carried through most calculations to reduce the noise in the sensitivity function. 


$$
\frac{d T_{I C}}{d t}=\frac{d \bar{T}_{W A}}{d t}=\frac{d T_{S C}}{d t}=0
$$

Solving for the new tube wall temperature initial condition gives

$$
\overline{\mathrm{T}}_{I \mathrm{~A}}=\frac{\mathrm{T}_{I \mathrm{~A}}+\mathrm{T}_{I \mathrm{C}}}{2}=895.5 \mathrm{~F}^{\circ}
$$

therefore

$$
\overline{\mathrm{T}}_{W A}=\overline{\mathrm{T}}_{I A}-\frac{\mathrm{W}_{I} \mathrm{C}_{P I A}\left(\mathrm{~T}_{I A}-\mathrm{T}_{I C}\right)}{\mathrm{H}_{\text {WA }}}=872.4885 \mathrm{~F}^{\circ}
$$

but

$$
\overline{\mathrm{T}}_{S A}=\frac{\mathrm{T}_{S A}+\mathrm{T}_{S C}}{2}=760.1 \mathrm{~F}^{\circ}
$$

and

$$
\begin{aligned}
\mathrm{H}_{S S A} & =\frac{\mathrm{W}_{S A}\left(\mathrm{~h}_{S C}-\mathrm{h}_{\mathrm{SA}}\right)}{\left(\overline{\mathrm{T}}_{\mathrm{WA}}-\overline{\mathrm{T}}_{\mathrm{SA}}\right)}=8328507.3 \mathrm{Btu} / \mathrm{hr} / \mathrm{F}^{\circ} \\
& =\frac{328189.6}{\left(0.02518+\frac{29.484029}{h_{\mathrm{FS}}}\right)}
\end{aligned}
$$

so that

$$
\mathrm{h}_{\mathrm{FS}}=2072.6077 \mathrm{Btu} / \mathrm{hr} / \mathrm{F}^{\circ} / \mathrm{ft}^{2} \text {. }
$$


Therefore, to test for the sensitivity of $\mathrm{H}_{\mathrm{WA}}$, two simulation runs are made. One run should use the nominal value of $\mathrm{H}_{W A}$ and the other the $+1 \%$ value. Equation $(2-5)$ is applied to yield the plots in Figure 2-2.

\section{A.2 $C_{\text {PWA }}$ Sensitivity}

The nominal value of $C_{P W A}$ is $0.12 \mathrm{Btu} / 1 \mathrm{bm} / \mathrm{F}^{\circ}$. Increasing this value by $1 \%$ yields $0.1212 \mathrm{Btu} / \mathrm{lbm} / \mathrm{F}^{\circ}$. From equation $(\mathrm{A}-2)$ at steady state it can be seen that $C_{\text {PWA }}$ does not affect the initial conditions of any of the state variables and parameters. Therefore the design conditions are already met and rebalancing is not necessary. 
APPENDIX B

\section{SENSITIVITY OF DOPPLER FEEDBACK COEFFICIENT}

The procedure outlined in Section 3.2 .1 will now be applied to determine the sensitivity of the Doppler coefficient.

1. Increasing the DC by $1 \%$, we get $D C_{+1 \%}=.005858$.

2. The $D C$ is used in the following reactivity feedback equation

$$
\begin{aligned}
P_{F B} & =(100 \times D C / \beta) \ln \left(\frac{460+\bar{T}_{F}}{460+T_{I}}\right)+\operatorname{AXECC}\left(\bar{T}_{F}-T_{I}\right) \\
& +\operatorname{SODDCC}\left(\bar{T}_{P I}-T_{I}\right)+\operatorname{RECC}\left(T_{P I}-T_{I}\right) .
\end{aligned}
$$

Increasing $\mathrm{DC}$ by $1 \%$ will cause a greater initial reactivity feedback. To compensate for this the steady state control rod position was adjusted.

3. The sensitivity function was applied and the primary loop model was simulated at steady state. Ideally the sensitivity function should be zero at steady state. However, because of a balancing error in step 2 and computer round off error, there will be some noise in the sensitivity function.

4. The simulator was then run for $120 \mathrm{sec}$ following a $10 \mathrm{c}$ step in reactivity. Figure $B-1$ is a sample sensitivity function plot for the fuel temperature. The noise found in step 3 is also plotted. 


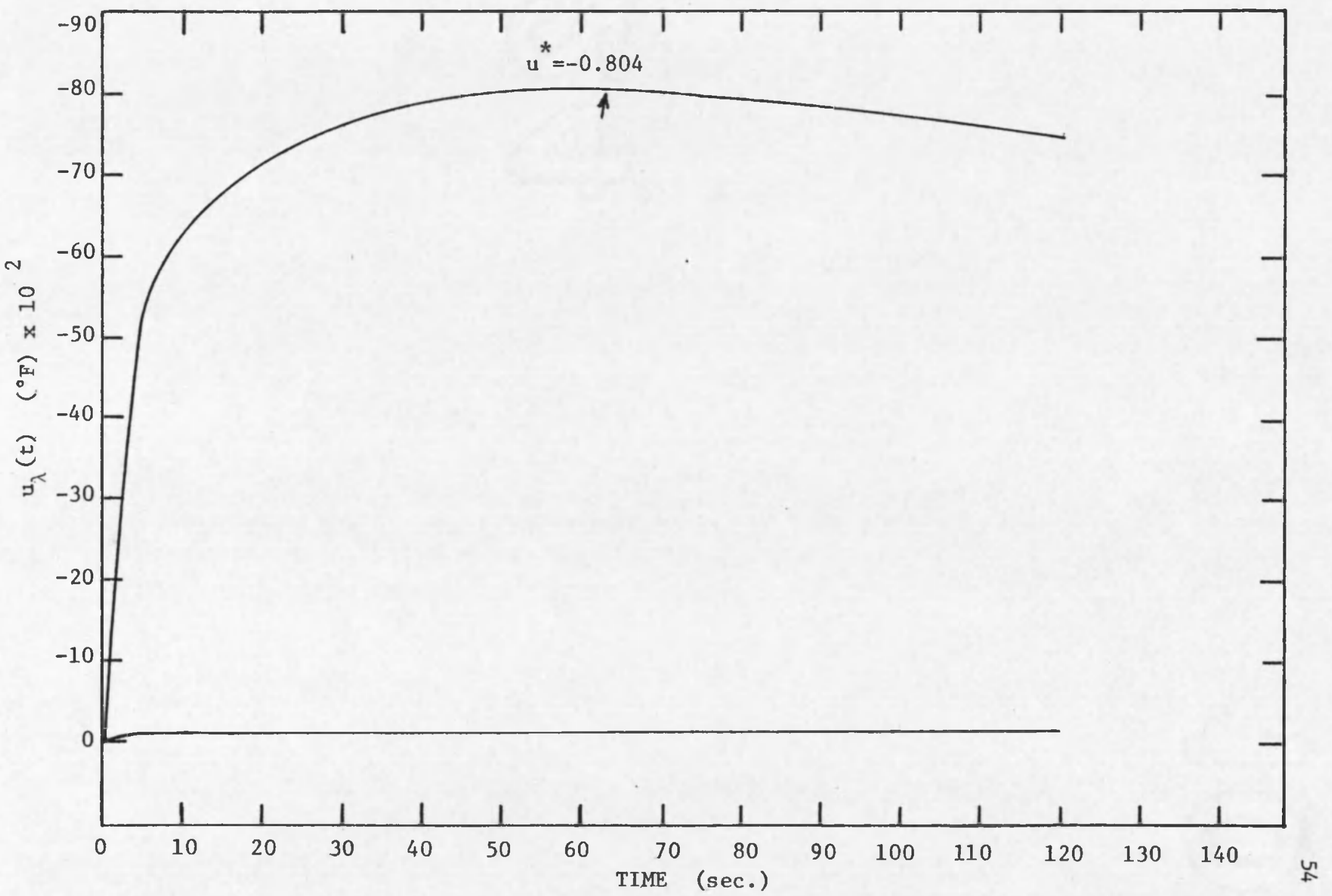

Figure B-1 -- Doppler Feedback Coefficient Sensitivity of the Fuel Temperature Following a $10 c$ Step in Reactivity. 
5. From Figure $B-1$ it can be seen that the noise is neglible.

6. A good sensitivity measure has been determined.

7. From Figure B-1, the peak sensitivity has been found to be -0.80 .

Figure B-2 shows the sensitivity function applied to the state variable $T_{P 7}$ both with and without feedback from the steam generator. It can be noted that both runs are essentially the same up to the 120 second cutoff time. 


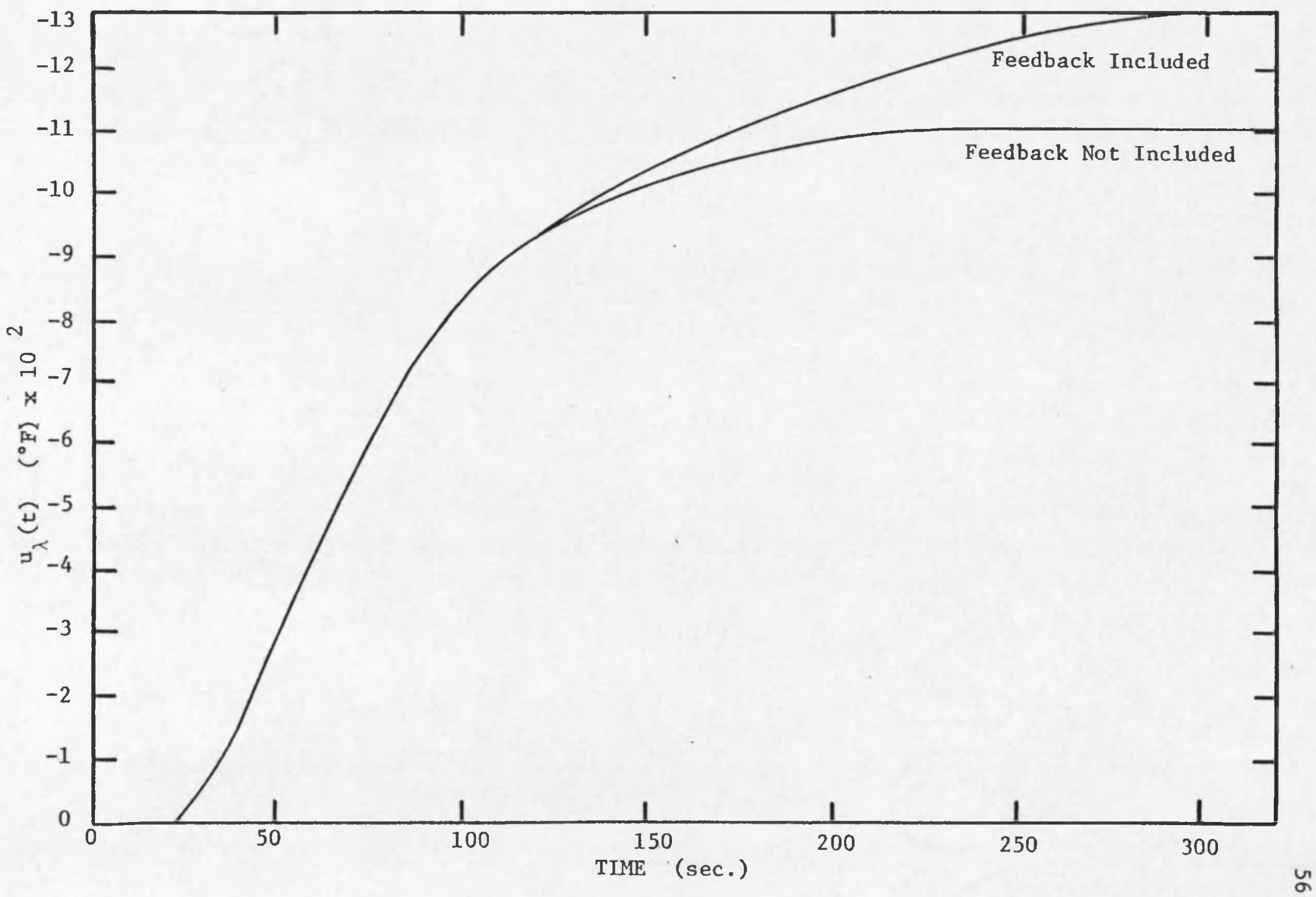

Figure B-2 -- Effects of Steam Generator Feedback on the Sensitivity of the IHX Intermediate Sodiun Outlet Temperature. 


\section{AN EXAMPLE OF INSENSITIVITY OF CERTAIN PARAMETERS}

The momentum equation for the primary loop is of the form

$$
\begin{aligned}
\frac{d W_{P S}}{d t} & =\frac{1}{A}\{\text { sum of elevation head terms }+ \text { pump head } \\
& \left.-W_{P S}{ }^{2} \text { [sum of constant friction factors] }\right\}
\end{aligned}
$$

where

$$
\begin{aligned}
& A \equiv \text { constant } \\
& W_{P S} \equiv \text { primary flow rate }
\end{aligned}
$$

If one of the friction factors is varied by $1 \%$, the momentum equation is unbalanced at steady state ( $\operatorname{set} \frac{d W_{P S}}{d t}=0$ ). Therefore to rebalance the loop, either the elevation head term, the pump head, or another friction factor must be adjusted. Since the first two terms are fixed due to design conditions, another friction factor must be readjusted. From the above equation it can be seen that the identity of a particular friction factor is lost because all of them are multiplied by the same $W_{P S}{ }^{2}$ term. Therefore the dynamics of the momentum equation will not be affected. 


\section{APPENDIX D}

ESTIMATION OF CUT-OFF TIME AT 40\% AND 70\% POWER LEVEL

Since the steam generator was not simulated at $40 \%$ and $70 \%$ power levels, it was not possible to observe the cut-off time needed to avoid significant feedback effects on the primary loop sensitivity runs. To estimate these times the following procedure was employed.

By direct observation of the simulation runs at the different power levels, it was noted that the following times were needed for the reactivity transient initiated in the reactor to reach the IHX.

\begin{tabular}{c|c} 
Power Leve1 & Time to IHX \\
\hline $100 \%$ & $28 \mathrm{sec}$ \\
$70 \%$ & $40 \mathrm{sec}$ \\
$40 \%$ & $70 \mathrm{sec}$ \\
\hline
\end{tabular}

At $100 \%$ power, it will be remembered that 120 seconds was chosen as the cut-off time. This implies that approximately 94 seconds was the time required for the feedback effects to travel the intermediate loop (i.e., $120-28=94$ ).

The mass in the intermediate loop is the same at all power levels and the following equation may be written

$$
\text { Mass in Loop }=\mathrm{W}_{100} \mathrm{t}_{100}=\mathrm{W}_{70} \mathrm{t}_{20}=\mathrm{W}_{40} \mathrm{t}_{40}
$$


where

$$
\begin{aligned}
& \mathrm{W}_{\mathrm{N}} \equiv \text { flow rate at power level } \mathrm{N} \\
& t_{\mathrm{N}} \equiv \text { time required for flow to travel the loop at power level } \mathrm{N} .
\end{aligned}
$$

Assuming that the time constants for heat transfer in the different components in the steam generator are the same at all power levels, a rough estimate can be made of the cut-off time by adding the observed time to reach the IHX with the time calculated from equation (D-1). Therefore:

at $70 \%$ power $\quad 40 \mathrm{sec}+\frac{W_{100^{t} 100}}{W_{70}}=180 \mathrm{sec}$,

and

$$
\text { at } 40 \% \text { power } \quad 70 \mathrm{sec}+\frac{W_{100^{t} 100}}{W_{40}}=330 \mathrm{sec} \text {. }
$$




\section{APPENDIX E}

AN EXAMPLE OF PUTTING FIRST ORDER BOUNDS ON A STEP REACTIVITY TRANSIENT

For this example, assume that the uncertainties in DC and AXECC are $\pm 20 \%$ and $\pm 10 \%$ respectively. From the magnitudes of their peak sensitivities found in Table 3-2 and with use of equation (3-2), the bounds on the fuel temperature following a $10 \mathrm{c}$ step in reactivity can be estimated as

$$
\varepsilon_{\bar{T}_{F}} \simeq|-0.80| * 20+|-0.32| * 10= \pm 19.2 \mathrm{~F}^{\circ} .
$$

In a similar manner, approximate bounds can be put on the other safety related state variables located throughout the primary loop.

As a check, a computer run was made which showed the actual bounding tolerance. Results comparing the estimate with the actual bounding tolerances are listed below.

State Variable

\section{Estimate}

$\overline{\mathrm{T}}_{\mathrm{F}}$

$\mathrm{T}_{\mathrm{P} 3}$

$\mathrm{T}_{\mathrm{P} 4}$

$\mathrm{T}_{\mathrm{P} 7}$

TI3

$T_{P I}$ $\pm 19.2 \mathrm{~F}^{\circ}$

$\pm 3.59 \mathrm{~F}^{\circ}$

$\pm 2.88 \mathrm{~F}^{\circ}$

$\pm 0.60 \mathrm{~F}^{\circ}$

$\pm 2.23 \mathrm{~F}^{\circ}$

$\pm 0.50 \mathrm{~F}^{\circ}$
Actual

$\pm 16.6 \mathrm{~F}^{\circ}$

$\pm 3.13 \mathrm{~F}^{\circ}$

$\pm 2.5 \mathrm{~F}^{\circ}$

$\pm 0.51 \mathrm{~F}^{\circ}$

$\pm 1.92 \mathrm{~F}^{\circ}$

$\pm 0.43 \mathrm{~F}^{\circ}$ 
It can be noted that in this case the estimate is conservative with regard to reactor safety.

Bounding estimates can also be made on other magnitudes of step reactivity transients by applying the superposition property of Inear differential equations. To include this feature, equation (3-2) can be written as

$$
\varepsilon_{S V} \simeq \frac{X}{I 0} \sum_{i=I}^{n}\left|u_{\lambda_{i}}^{*}\right| T_{\lambda_{i}}
$$

where $\mathrm{X}$ is the magnitude of the step in reactivity expressed in cents. 


\section{REFERENCES}

Chang, Sen-I, and T. W. Kerlin. "A Method for Systematic Interpretation of Dynamic Measurements in a High Temperature Gas Cooled Reactor," Ph.D. Dissertation, The University of Tennessee, 1976.

Clinch River Breeder Reactor Project, Preliminary Safety Analysis Report. Project Management Corporation, 1975.

Haberman, D. "A Minimal Sensitivity Design Method for Control Systems," Ph.D. Dissertation, The University of Arizona, 1977.

Lucas, J. L., and J. V. Wait. DARE-P, A Portable CSSL-type Simulation Language. Simulation, January 1975.

Shinaishin, M. A. "Dynamic Simulation of Sodium Cooled Fast Reactor Power Plant," Ph.D. Dissertation, The University of Arizona, 1976. Published as U.S. Nuclear Regulatory Commission Report No. NUREG-0110.

Tomovic, R. Sensitivity Analysis of Dynamic Systems. McGraw-Hi11, 1964.

Truxal, J. G. Automatic Feedback Control System Synthesis. Chapter 5, p. 295, McGraw-Hill, New York, 1955.

Van Ness, J. E., J. M. Boyle, and F. P. Imad. "Sensitivities of Large Multiple-Loop Control Systems," IEEE Transactions on Automatic Control, July 1965.

White, R. C., Jr. "Sensitivity and State Variable Feedback," M.S. Thesis, The University of Arizona, 1967. 
